\title{
El alminar califal de la Ermita de Santiago del Camino en Medina Sidonia (Cádiz)
}

\author{
Pedro Gurriarán Daza * \\ Carlos Gómez de Avellaneda Sabio * \\ Ángel J. Sáez Rodríguez *
}

\begin{abstract}
RESUMEN
La ermita que, bajo la advocación del apóstol Santiago, se sitúa en las inmediaciones de Medina Sidonia (Cádiz), cuenta con una torre almenada de extraordinario interés. Fue, en su origen, una construcción islámica medieval, arruinada en su momento y reconstruida después como torre fortificada para dar protección a los campesinos de la zona. Se trata en concreto del único alminar de época omeya, con aparejo de soga y tizón de tipo califal, que se conoce hasta el momento fuera de Córdoba. Su cronología puede situarse a finales del siglo $X$, tanto por la citada característica constructiva (medidas y disposición) como por su planta cuadrada, organizada en torno a un machón central también cuadrangular; asimismo por la solución del abovedamiento de los tramos escalonados y el tipo de mortero empleado. En el conjunto arquitectónico se identifica diverso material de acarreo de época preislámica, si bien no está confirmada la existencia en este lugar de ninguna construcción previa a la mezquita a la que asociamos el alminar.
\end{abstract}

PALABRAS CLAVE: Alminar, mezquita, soga y tizón, Califato, Medina Sidonia.

\section{INTRODUCCIÓN}

Con la presente publicación queremos dar a conocer los primeros resultados de un trabajo de investigación sobre la ermita de Santiago del Camino o de Los Santos en Medina Sidonia (Cádiz), ejemplo de cómo la paciente aplicación de métodos que intentan ser rigu-

\begin{abstract}
The hermitage under the narre of Santiago Apostol, which is placed in the surroundings of Medina Sidonia, posseses an extraordinary interesting tower with battlements. It was originally a maedieval muslim building partially devasted and rebuilt as a fortified tower to protect the peasants in the area. It is actually the only minaret from an Omeya Age with a caliphal ashllar work which is known until this moment out of Cordoba city. Its chronology may be settled at the end of the I Oth century not only due to its building features (measurements and location) but also by its square floor, organized around a wide pillar and the type of pointed ceiling in the stepping places and the cement used. In this building we can identify some material from the premuslim time, although it is not proved the existen- ce in this place of any building previous to the mosque we have related to the minaret.
\end{abstract}

KEY WORDS: Minaret, mosque, Caliphate, Medina Sidonia

rosos tiene a veces una feliz recompensa. Nos centraremos en este primer artículo en el elemento arquitectónico de mayor singularidad que forma parte del conjunto, concretamente una torre prismática cuya fase constructiva original respondería a un alminar erigido en periodo califal. La trascendencia del descubrimiento está justificada dada la escasez de alminares res-

* Instituto de Estudios Campogibraltareños. 
tantes de dicho momento, circunscritos la mayoría de ellos, además, a la propia Córdoba. El buen estado de conservación de sus estructuras, aparejadas según la clásica sillería a soga y tizón, nos sirven, igualmente, para conocer un poco más las técnicas edilicias del momento y la difusión de esta característica fábrica más allá de la metrópoli omeya. En cualquier caso, la vida útil de esta torre, religiosa e islámica en su origen, tiene una sorprende continuación con su recrecido como obra militar ya bajo dominio castellano, probablemente vinculada a la inseguridad que reinaba en los campos de la zona a finales del siglo XIII y principios del XIV En ese momento se establecería el culto cristiano en la ermita bajo la advocación del apóstol Santiago, sin que influyera en ello el carácter fortificado de la torre anexa, que daría servicio a la población de los campos cercanos.

\section{SITUACIÓN Y DEFINICIÓN DEL CONJUNTO MONUMENTAL}

La geografía es, desde luego, un gran condicionante de las actuaciones humanas, y en el caso de Medina Sidonia, explica muchas cuestiones. La ciudad histórica se levanta sobre una gran colina aislada, rodeada de fértiles campos, y en posición central en la provincia de Cádiz (Fig. I). Constituye un notable nudo de comunicaciones, al cruzarse allí muchas rutas, siendo la más importante de éstas la que desde el puerto de Barbate conecta la costa con Medina Sidonia y se prolonga hasta Sevilla y la Vía de la Plata .

Medina Sidonia fue Asido, ya importante en época alto imperial, pero que tras la crisis del siglo III y la decadencia casi total de las ciudades costeras (Carteia, Belo, Gades, etc.), por su posición estratégica y ventajas tácticas para la defensa, heredó las funciones de capitalidad de Gades y Carteia. Constituyó pieza funda- mental en el dominio bizantino del sur peninsular, sede de un obispado, y única ciudad de la zona que ofreció fuerte resistencia a los invasores musulmanes a comienzos del siglo VIII. Al principio de la dominación islámica, el territorio del obispado se transformó en una kura, pronto escindida en dos ante el éxito y desarrollo de Algeciras, heredera de Carteia y Belo en la función de paso del Estrecho. Las periódicas rebeliones que se suceden con carácter habitual hasta su pacificación durante el siglo $X$, con los episodios comunes de "encastilla- miento" en las alturas, hacen que los gobernantes de Córdoba trasladen la capital de la provincia a Calsena (Qalsana) ${ }^{2}$, ciudad abierta y en Ilanura, de efímera vida, ya que no sobrevivió a los grandes disturbios de la fitna de comienzos del siglo Xl. La capitalidad e importancia de Medina Sidonia (Madinat Saduna, luego también referida como Madinat Ibn al-Salim) languidece a partir de entonces y se desplazará progresivamente hacia el eje formado por Arcos y Jerez durante los periodos de taifas y de los imperios norteafricanos, para pasar a ser adelantada cristiana en la frontera tras la recuperación castellana de Andalucía Occidental.

La ermita de Santiago del Camino se sitúa a mediodía del casco urbano de Medina Sidonia, aislada a escasos mil metros de distancia del cerro donde se yergue el castillo de dicha población, con el cual tiene relación visual directa (Fig. 2). Sus coordenadas U.T. M. son: X, 237.343; Y, 4.037.983; Z, I I 3 m.s.n.m. De este modo, el edificio se levanta en un terreno que cae con suave pendiente hacia el $\mathrm{SO}$, formando las primeras estribaciones de la elevación que alberga a la población adyacente; a continuación el paisaje se torna monótono, con una sucesión de fértiles llanuras salpicadas por lomas de escasa altitud.

Este templo medinense ha llegado a nuestros días como el resultado de un conjunto de

\footnotetext{
I Consúltese de este modo el recorrido interior que propone al-Idrisi para ir desde Algeciras hasta Sevilla; AL-IDRISI, Description de I'Afrique et de l'Espagne, trad. R. Dozy y M. J. de Goeje, Amsterdam, 1969, pp. 214 y 215.

2 Allí se reunirá la población disidente tras bajarla de sus fortalezas; IBN HAYYAN, Crónica del califa 'Abdarrahman III an-Nasir entre los años 912 y 942 (al-Muqtabis V), trad. M. J. Viguera y F. Corriente, Zaragoza, 198I, p. 167.
} 
actuaciones arquitectónicas puntuales e independientes que han configurado el carácter general de todo el edificio a lo largo de los siglos (Fig. 3). Las distintas piezas gravitan en torno a un oratorio de planta basiícal cuyos pies miran hacia el SO. La sala de preces, de tres naves, con mayor latitud la central, y tres tramos, es hipóstila, y en ella encontramos abundante material de acarreo de origen preislámico como capiteles romanos y visigodos, pilastras, etc. La cabecera se resuelve mediante un ábside de trazado octogonal con perímetro exterior cuadrado. En cualquier caso, y con independencia de todo el material clásico reaprovechado, el oratorio actual denota un claro ascendente mudéjar, estilística que, curiosamente, y dado su interés, no ha sido aún estudiada con carácter exhaustivo en este edificio.

En la nave lateral izquierda de la sala de oración desemboca una amplia habitación que actualmente ejerce el papel de sacristía. Comunicada con ésta, y con sus accesos casi enfilados, sigue una vasta habitación que denominaremos "módulo mudéjar", cubierta con bóveda vaída, y vinculada especialmente a la torre, a la cual se adosa (Lám. I ). Su situación, el grosor de sus muros y las características de su acceso (con mochetas y gorroneras) justificarían un origen exento junto a la citada torre, que aparece en el extremo NO del conjunto; posteriormente se comunicaría con la sala de oración mediante esa estancia que actualmente sirve de sacristía. Durante el último siglo, la ermita ha recibido nuevas construcciones que han terminado por conferirle su configuración actual; destaca, sobre todo, el gran bloque adosado junto a la nave lateral izquierda del templo, que servía, entre otros, para usos escolares, así como los aseos que se situaron en el muro septentrional del módulo mudéjar.

\section{ESTADO DE LA CUESTIÓN. ANTECEDENTES}

El edificio que nos ocupa presenta tradicionalmente gran interés historiográfico, y según recientes opiniones," "puede considerarse el templo cristiano en uso más antiguo de Andalucía" ${ }^{3}$, posibilidad a manejar con natural prudencia y que no es sino una más de las ofrecidas por este pequeño pero rico monumento, verdadero palimpsesto arquitectónico, testigo de muchas fases de la historia. Los enigmas arqueológicos planteados por la ermita no han sido resueltos, pues a pesar de los muchos y prestigiosos estudiosos que, a lo largo de los siglos se han ocupado def tema, faltan todavía trabajos arqueológicos que, unidos a exhaustivos análisis tanto de la arquitectura como de los elementos reutilizados, puedan explicar definitivamente la génesis y evolución del conjunto monumental. En espera de esas intervenciones, sirvan estas líneas para suscitar la atención de las instituciones pertinentes para que refuercen sus cuidados sobre un elemento patrimonial de gran valor.

Es en el siglo XVI, con los eruditos renacentistas, cuando se difunde por España la pasión por los vestigios materiales del pasado, ocupando un primer lugar, por razones obvias, los testimonios epigráficos. Así, alguien tomó conciencia de que en la ermita de Santiago del Camino de Medina Sidonia, existían inscripciones latinas, referentes a un glorioso pasado religioso, en unión de restos arquitectónicos de la antigüedad clásica. Estos descubrimientos, en unión de tradiciones y fuentes literarias, configuran una interpretación en clave piadosa del lugar, siendo eco de esta corriente estudiosos como Barrantes Maldonado en el siglo XVI ${ }^{4}$, Gerónimo de la Concepción en el siglo XVII ${ }^{5}, \mathrm{u}$ otros como el padre Flórez o Martínez Delgado en el siglo XVIII ${ }^{6}$. El estudio de tales inscripciones

3 E. J.VEGA GEÁN y F. A. GARCÍA ROMERO, Origen e historia del antiguo obispado asidonense, Cádiz, 1997, p. 52.

4 A. BARRANTES MALDONADO, Memorial Histórico Español, I54I, Ed. por la Real Academia de la Historia, Madrid, I875. G. DE LA CONCEPCIÓN, Emporio del Orbe, Cádiz ilustrado, Amsterdam, 1690.

6 E. FLÓREZ, España sagrada. Teatro Geográphico-Histórico de la iglesia de España, T.VII y X, I75I y |792. F. MARTíNEZY DELGADO, Historia de Medina Sidonia, manuscrito de finales del siglo XVIII, publicado en Cádiz en 1875, bajo la supervisión de J. M. Enrile. 
se perfecciona en el siglo XIX con Hübner ${ }^{7}$, y ya en el siglo XX con Romero de Torres ${ }^{8}$ y Vives ${ }^{9}$, mientras se le presta muy escasa atención al resto del conjunto, por lo que resultan estudios que tratan en gran parte sobre los documentos epigráficos de un modo descontextualizado. No obstante, poco a poco se fue examinando mejor todo el conjunto de construcciones, y así, ya Martínez y Delgado considera como "de antiquísima fábrica" a la torre ${ }^{10}$, que Pardo de Figueroa estima como único resto del primitivo templo paleocristiano "Enrique Romero de Torres trata el tema, aparte de la epigrafía, considerando el cuerpo mudéjar anexo a la torre como la primitiva iglesia ${ }^{2}$, mientras que César Pemán realiza en 1930 un escueto pero acertado análisis, en gran parte no superado, donde ya aventura un origen islámico para la parte baja de la torre ${ }^{13}$.

El edificio se ha visto incluido en estudios de carácter general que corroboran su importancia ${ }^{14}$, elaborándose a lo largo del tiempo una "versión tradicional" poco a poco enriquecida, aún- que a menudo pintoresca, y que viene a ser así:

- La ermita, según tradiciones locales y eruditas, se debe a S. Paulino de Nola, muriendo en el martirio en el mismo lugar algunos de los discípulos del Santo, a fines del siglo IV o principios del $V^{15}$. Varios autores, ante la presencia de material de acarreo romano, proponen incluso la existencia de una villa, algunas de cuyas dependencias se dedicaron a uso religioso.

- Una inscripción ha hecho pensar en un personaje llamado Lepero como partícipe de la edificación, sin embargo, parece indudable que otra inscripción es alusiva a la consagración por el obispo Pimenio, en época visigoda, de éste o de otro edificio no muy lejano, en el caso que dicha pieza fuera de acarreo.

- Se supone, según las opiniones tradicionales, una cierta supervivencia del culto cristiano en el periodo islámico, pero es indudable que la ermita como tal es en gran medida obra posterior a la Reconquista, conociéndose bajo la advocación del apóstol Santiago ${ }^{16}$.

Todas estas cuestiones referentes a la ermita como conjunto arquitectónico se encuentran en proceso de estudio, y no las debatimos aquí, limitándonos al avance de las conclusiones sobre un único elemento, la torre, como paso previo a la publicación del monumento en sus demás fases.

7 A. HÜBNER, Inscriptiones Hispaniae christianae, Berlín, 187 I.

8 E. ROMERO DE TORRES, "Inscripciones romanas y visigodas de Medina Sidonia, Cádiz y Vejer de la Frontera", Boletín de la Real Academia de la Historia, № 54, Madrid, 1909, pp. 91 y ss.

9 J.VIVES, Inscripciones cristianas de la España Romana y Visigoda, Barcelona, 1942. i o Véase, F. MARTíNEZY DELGADO, Op. Cit., I875, p. 172.

I I M. PARDO DE FIGUEROA, Planos y noticias del Alcázar y Castillo de la ciudad de Medina Sidonia, manuscrito en la biblioteca de la Real Academia de la Historia, p. 48.

I2 E. ROMERO DE TORRES, Catálogo Monumental de lo provincia de Cádiz, Madrid, 1934, pp. 263 a 269.

13 Consúltese, C. PEMÁN, “El material visigodo de la Ermita de los Santos de Medina”, Boletín del Museo de Bellas Artes de Cádiz, Nº 14, Cádiz, 1930, pp. 31 a 36.

I4V. LAMPÉREZY ROMEA, Historia de lo Arquitectura Cristiana Española en la Edad Media, I, I930; C. PEMÁN, Memoria sobre la situación arqueológica de la provincia de Cádiz en 1940, Madrid, I954; P. ANTÓN SOLÉ y A. OROZCO ACUAVIVA, Historia medieval de Cádiz y su provincia a través de sus castillos, Cádiz, 1976; M. RAMOS ROMERO, Medina Sidonia. Arte, historia y urbanismo, Cádiz, 1981; F. SALVADOR VENTURA, Hispania Meridional entre Roma y el islam. Economía y sociedad, Granada, I990; R. CORZO SÁNCHEZ, "Arqueología del Obispado Asidonense", Isidorianum 2, Sevilla, 1992, pp. 7 y ss; E. J.VEGA GEÁN y F. A. GARCÍA ROMERO, Op. Cit., 1997.

15 Tradición que fue recogida principalmente por F. P. DEL CAMPO en su Historia general de los Ermitaños de la Orden de San Agustín.

I6 Lo que vendría a demostrar que en los últimos tiempos medievales se ignoraba la importancia del templo en época antigua. Por ello, lo relativo a los santos se reivindica en el renacimiento al poder leerse las inscripciones. 


\section{LA TORRE COMO ALMINAR}

\section{I. Análisis arquitectónico y morfológico}

\section{I.I. Relación torre-mezquita; ubicación}

A la hora de definir cómo se implantan los alminares en las mezquitas andalusíes hemos de tener en cuenta, en primer lugar, que esta construcción utilitaria era absolutamente prescindible, ya que, para cumplir su cometido, los almuédanos podían recurrir a cualquier torre próxima al recinto sagrado ${ }^{17}$. Es decir, aunque es posible la identificación de oratorios sin alminares, la mayoría de las fundaciones estudiadas presentan dichas torres construidas, ex profeso, en su solar. La indudable tradición arquitectónica de los alminares en al-Andalus nos permite identificar recios cánones relacionados tanto con su ubicación dentro del espacio sacro como con la forma de vincularse con las distintas piezas que conforman la mezquita. De este modo, se comprueba cómo en los oratorios andalusíes la costumbre morfológica y edilicia adoptará en los alminares una serie de hábitos que evolucionarán según una clara secuencia diacrónica; esta circunstancia se manifestará muy útil a la hora de estudiar e identificar estas singulares construcciones, tal es nuestro caso.

Como norma general, la situación de los alminares del Islam al-Aqsa nunca sobrepasará el límite existente entre sahn (patio) y haram (sala de oración), y, salvo casos excepcionales ${ }^{18}$, tenderán a levantarse aislados en los muros perimetrales que circundan el patio de abluciones. Aunque suelen estar dispuestos en el muro opuesto a la qibla, enfrentados de forma axial al mihrab, como predomina en alAndalus hasta mediados del siglo $X$, o en los vértices, como es costumbre a partir de entonces, excepcionalmente pueden aparecer en los otros muros del patio, tal es el caso singular de la Giralda.

Estudiando tanto la relación que existe entre las distintas construcciones que integran en la actualidad la ermita de Santiago del Camino, como la organización general de su planta, puede verificarse cómo la situación de la torre en el vértice $\mathrm{NO}$ del conjunto es la adecuada y, hasta cierto punto, necesaria a la hora de hablar de un hipotético alminar (Lám. 2 y Fig. 3). Para ello hemos de partir de una serie de "apriorismos" básicos: Suponemos que la sala de preces actual viene a ocupar de forma aproximada el emplazamiento del haram del desaparecido oratorio islámico, cambiando el «sentido de la oración hacia levante, mientras que el patio inmediato, de similar proporción a éste, aunque hoy día completamente ilegible, serviría de nexo con la torre. Así, la situación tangencial de la torre con relación a este desaparecido sahn, y su localización en el extremo septentrional del mismo, será la que con carácter habitual encontremos en numerosas mezquitas andalusíes.

Sin embargo, hemos de tener en cuenta que este esquema de situación tan común en el Occidente musulmán no lleva implícito un

17 Sin ir más lejos, la primitiva mezquita mayor cordobesa recurrió, en un primer momento, a una torre del vecino alcázar como alminar, por una simple "pobreza de recursos", según argumenta Torres Balbás; véase, según referencia del Ajbar machmu'a, L. TORRES BALBÁS, "Arte hispanomusulmán hasta la caída del califato de Córdoba", España Musulmana hasta la caída del califato de Córdoba (7I I-103 I). Historia de España dirigida por Ramón Menéndez Pidal, tomo V, Espasa Calpe, Madrid, 1957, p. 34I. También se puede identificar la ausencia de esta construcción, por ejemplo, en la mezquita de la alcazaba de Vascos, para cuyo recurso se emplearía, quizás, alguna torre de las estructuras defensivas vecinas. De la mezquita del Cristo de la Luz no se conserva resto alguno de alminar, y, probablemente, no lo haya poseído nunca; similar circunstancia podemos apuntar para el oratorio almohade conservado en la localidad almeriense de Fiñana.

I 8 Por ejemplo, la mezquita de Mértola, según hipótesis de Christian Ewert, poseía su alminar adosado directamente al muro de cierre NO de la sala de preces, actuando de contrafuerte; C. EWERT, "La mezquita de Mértola (Portugal)", Cuadernos de la Alhambra, N 9. Granada, 1973, p. 33. De igual modo, en Almonaster la Real el alminar aparecería completamente aislado, sin vínculo alguno con el sahn; consúltese la restitución hipotética de la mezquita en A. JIMÉNEZ MARTíN, La mezquita de Almonaster, Diputación Provincial de Huelva, Huelva, 1975, Fig. 12. Señalemos, por último, que el oratorio rural excavado recientemente en el cortijo del Centeno (Lorca, Murcia) parece disponer su alminar junto al haram en el vértice NO, y sin relación con un patio que, sencillamente, no existe; véase, A. PUJANTE MARTíNEZ, “La mezquita rural de la alquería del cortijo del Centeno", Revista de Arqueología, N²34, Madrid, 200।, pp. 42 a 49 
margen temporal preciso que permita arrojar una fecha para la construcción de la torre, ya que la horquilla cronológica que abarca va desde el siglo $X$ hasta prácticamente las últimas construcciones de este tipo identificadas en la península Ibérica. Del primer alminar del cual tenemos un claro testimonio arqueológico, el erigido por el emir Hixam I en la aljama cordobesa, sabemos que se enfrentaba casi a eje con el muro de la qibla, desplazándose ligeramente a poniente para dejar sitio a la Bab abSawmu 'a a través de la cual se accedía al patio ${ }^{19}$. Este esquema, que además triunfará simultáneamente en el norte de África como vemos en la gran mezquita de Qairawan ${ }^{20}$, se repetirá en numero sas mezquitas andalusíes del Emirato de las cuales disponemos de un cierto conocimiento topográfico de sus plantas generales; así se comprueba, por ejemplo, en varias mezquitas mayores como la de Zaragoza ${ }^{21}$, la sevillana de Ibn 'Adabbas 22, la priora' de Santa María de Carmona, además de la erigida en Madinat alZahra', este último ejemplo ya de pleno siglo $X$. Será en esta centuria cuando se desarrolle una nueva forma organizativa que tienda a desplazar los alminares hasta los vértices del sahn, circunstancia que se aprecia en numerosos oratorios como los cordobeses de San Juan, Santa Clara y El Fontanar ${ }^{23}$, en la torre de Santa María de la Granada de Niebla, y, ya en el siglo $X \mathrm{l}$, en el alminar granadino de San José. Exceptuando el caso onubense, todas estas mezquitas serían simples oratorios de barrio, circuns- tancia que podría llevar implícita una primera segregación morfológica entre aljamas con torres axiales y recintos menores con torres excéntricas, al menos en periodo omeya, y según lo poco que sabemos en virtud a las escasas construcciones de este tipo documentadas.

Apuntemos, por su interés, cómo en un primer momento algunos alminares tienden a traspasar en su totalidad la línea de cierre septentrional de los patios, tal y como se ve en las aljamas de Córdoba y Sevilla, proceder que bien podemos tildar de arcaico al no triunfar en momentos posteriores al siglo IX ${ }^{24}$, sobre todo a raíz de la progresiva ubicación tangencia' de las torres. En este último caso, los muros del patio se suelen alinear con los del alminar, a pesar de que, en ocasiones, este último sobresalga ligeramente ${ }^{25}$.

Según lo expuesto, la ubicación septentrional y tangente de esta torre de Medina Sidonia en relación con el resto de las construcciones conservadas de la ermita, responde a la vista en las mezquitas menores andalusíes que triunfan a partir del siglo $X$, sin que se pueda aportar una mayor precisión a esta fecha, que actuará a modo de término post quem. A partir de la hipótesis planteada para el contorno del sahn, se estima como probable que el desaparecido muro NO del mismo enrasara con el frente correspondiente de la torre. El contacto entre ambos se resolvería mediante su sim-

19 Véase, F. HERNÁNDEZ GIMÉNEZ, El codo en la historiografía árabe de la Mezquita Mayor de Córdoba. Contribución al estudio del monumento, Madrid, I96I, p. 34.

20 Se construye esta torre en tiempos del príncipe aglabí Ziyadat Allah en el ato 221 H/836, según se refiere en K. A. C. CRESWELL, Compendio de Arquitectura Paleoislámica, Ed, y apéndice de A. Jiménez, Sevilla, 1979, p. I45. Nótese, además, cómo las grandes mezquitas construidas por las autoridades abbasíes en Samarra durante el siglo IX igualmente situarán sus alminares a eje, aspecto que se recogerá en la posterior mezquita de Ibn Tulun en al-Fustat, cuya torre es rematada por una malwiya similar a las samarríes.

2I La mezquita mayor de Saraqusta, de la que se supone su origen en tiempos de la conquista, sufre ampliaciones en el siglo IX, bajo el emir Muhammad I, y luego por el régulo taifa Mundir Ibn Yahya al-Tuyibí, durante el primer cuarto del siglo XI. A este momento parece responder la impronta del alminar estudiada por A. ALMAGRO GORBEA, "El alminar de la mezquita aljama de Zaragoza", Madrider Mitteilungen, 34, 1993, pp. 341 y 342, Fig. 6.

22 Es datada esta mezquita en tiempos del emir 'Abd al-Rahman II, bajo la dirección del cadí de Sevilla "Umar Ibn 'Adabbas en el año 214H/829-830; véase, L. TORRES BALBÁS, "La primitiva mezquita mayor de Sevilla", al-Andalus, XI, Madrid-Granada, 1946, p. 427.

23 Consúltese, D. LUNA OSUNA, A. M. ZAMORANO ARENAS, “La mezquita de la antigua finca 'El Fontanar (Córdoba)”, Cuadernos de Madinat al-Zahra, Vol. 4, Córdoba, "I999, p. 153.

24 Refiere esta cuestión al referirse al alminar de la primera aljama de Sevilla, F. HERNÁNDEZ GIMÉNEZ, El alminar de 'Abd al-Rahman III en la Mezquita Mayor de Córdoba. Génesis y repercusiones, Granada, 1975, pp. I79 y I 80.

25 Tal es el caso, por ejemplo, del alminar almohade de Cuatrovitas; véase, P. GURRIARÁN DAZA, "Acerca del alminar almohade de Cuatrovitas en Bollullos de la Mitación (Sevilla)", Caetaria, 3, Algeciras, 2000, p. 167. 
ple adosado, sin enjarje, tal es la costumbre en este tipo de construcciones ${ }^{26}$. No obstante, el discreto testimonio de dicho cierre parece intuirse en las primeras hiladas de cimentación de la torre, donde se observa la presencia de un par de sillares en espera que garantizarían una mínima trabazón con un muro o estructura, hoy arrasada, pero que aún se insinúa en planta, que seguiría la alineación propuesta como cierre NO del patio. De este modo, el hecho de que el alminar no sobrepase la línea perimetral del sahn nos relaciona su construcción con algún momento posterior al siglo IX, cuando parece ser costumbre adoptar dicha disposición, confirmando, así, el espacio cronológico propuesto anteriormente a partir de su emplazamiento.

\section{I.2. Tipología del alminar; proporciones}

La torre de la ermita de Santiago de Medina Sidonia responde, en su fase fundacional, al tipo de construcción que, con carácter sistemático, sirve como alminar en las mezquitas del Islam al-Aqsa (Lám. 3). Nos estamos refiriendo a torres prismáticas de planta cuadrada, con machón nuclear alrededor del cual se organizan tanto las idas de la escalera como su abovedamiento. Solían rematarse con uno o varios cuerpos superpuestos, más discretos y remetidos con respecto a la caña principal, aunque en alAndalus sólo está documentada la existencia de alminares con simple linterna como remate. El almuédano accedía desde ésta a la terraza para proceder a la llamada a la oración. De forma tradicional se cita cómo esta tipología parece provenir de Oriente, donde el mundo omeya asimiló la tipología de ciertas torres de iglesia sirias ${ }^{27}$, aunque, por otra parte, no sería extraña la influencia ejercida por faros clásicos, aún existentes en el marco mediterráneo durante los siglos VII y VIII ${ }^{28}$.

Con independencia de estas cuestiones "genéticas", resulta evidente que el tipo que se implanta en el Occidente musulmán no experimenta apenas más evolución que la referida a su esbeltez y a sus diversos tratamientos de exorno, conservadurismo edilicio que no se aprecia tan claramente en Oriente, donde la formalización tipológica en alminares fluctúa geográfica y temporalmente de forma más rica y acusada. A pesar de ello, dicha tradición secular en las torres de al-Andalus y del Magreb se presta a sistematizarse estableciendo una secuencia evolutiva de las mismas, no tanto en lo referente al tipo, casi inamovible, como a su particular concepción volumétrica y epidérmica. Esta circunstancia, al igual que referíamos a la hora de estudiar la ubicación de los alminares en las mezquitas, se manifiesta sumamente útil en cuanto al conocimiento e identificación de estas construcciones se refiere.

A partir del alminar construido por Hixam I en la mezquita de Córdoba, de planta cuadrada y machón, aparentemente, de similar esquema, todos los demás ejemplos que conocemos siguen idéntico replanteo perimetral. Sin embargo, es necesario dar cuenta de un hiato en lo referente a la resolución de la estructura interior correspondiente al grueso de las construcciones emirales estudiadas, circunscritas, casi exclusivamente, a Córdoba, Sevilla y el área onubense, las cuales se organizan en torno a un grueso cilindro. De todos modos, pensamos que ambas costumbres edilicias debieron coexistir durante el siglo IX, aunque nos falten ejemplos ajenos al tipo cilíndrico. La llegada del Califato supondrá la desaparición de

\footnotetext{
26 Se comprueba esta circunstancia, por ejemplo, en el citado alminar de Cuatrovitas. Además, el estudio parietal de los alminares de San Juan de Córdoba y San José de Granada, hoy en día exentos, y anteriormente situados en el vértice norte del sahn, parece conllevar la inexistencia de enjarje con los muros del patio. Similar circunstancia se refiere para el alminar de Santa Clara de Córdoba con respecto al muro de cierre de la calle Oslo; consúltese, V. ESCRIBANO UCELAY, "Mezquita de la calle Rey Heredia", al-Mulk. Anuario de Estudios Arabistas, Córdoba, año 1964-65, p. 87.

27 Entre los autores clásicos, defiende esta tesis, por ejemplo, K. A. C. CRESWELL, Op. Cit., I979, pp. $\mid 45$ y 146.

28 A la clásica referencia del Faro de Alejandría, habría que añadir la referencia indiscutible que ejercerían en la península lbérica construcciones como la Torre de Hércules de A Coruña, así como el templo heracleo de Cádiz, de cuya organización general ofrecen un preciso testimonio las fuentes; véase al respecto AL-HIMYARI, La péninsule ibérique au Moyen Age d'aprés le AKitab ar-Rawd al-Mi'tar, trad. de E. Lévi-Provencal, Leiden, París, 1938, pp. I74 y 175.
} 
este último esquema y la definitiva implantación de las torres de machón cuadrado; el nexo y transición entre ambos modelos lo encontramos, por ejemplo, en el alminar de la mezquita aljama de Madinat al-Zahra ', con núcleo ochavado. La mayor esbeltez que empieza a predominar en ese momento (véase infra) parece llevar asociado el triunfo de las construcciones con machón cuadrado, aunque el tipo no debió de inspirar aún suficientes garantías estructurales como para solucionar construcciones próceres, como sucede en el primer cuerpo del alminar de 'Abd al-Rahman III de la aljama cordobesa, resuelto con doble escalera. Con independencia de esas cuestiones, en la fase fundacional de la torre de Santa Clara de Córdoba, datada a finales del siglo $X^{29}$,ya aparece el esquema nuclear definitivo de alminar modesto que triunfará en al-Andalus a partir de entonces, y cuya secuela inmediata la encontramos en la torre zirí de San José de Granada ${ }^{30}$.

Otro aspecto de indudable interés a la hora de estudiar el proceso evolutivo de los alminares andalusíes es el referido a su esbeltez, tema ampliamente estudiado por la historiografía tradicional. Así, es conocido cómo las más antiguas construcciones de este tipo ajustaban sus primeros cuerpos a una proporción basealtura dupla, circunstancia que se comprueba al analizar todas las torres del siglo IX cuyo alzado se conserva. Con el alminar de San Juan de Córdoba, de finales del siglo IX O principios del siglo $X$ según Félix Hernández 31, aparece por vez primera el módulo triple, común a otras torres documentadas de los siglos $X$ y XI. Sin embargo, tras la proclamación del Califato, el proceso de estilización se acentuará tras alcanzar el nuevo alminar de la aljama cordobesa una proporción de 1/3.63 para su cuerpo inferior 32 , llegándose, incluso, a relaciones puntuales de base-altura de 1/4 en las torres de las mezquitas de los Andalusíes y la Qarawiyyin de Fez, promovidas por autoridades omeyas ${ }^{33}$. Aunque esta última proporción suela relacionarse con alminares propios del mundo almohade, la presencia de estas estilizadas construcciones magrebíes no descarta que, al menos un par de siglos antes, ya fuera común el proyecto de torres con estas características.

Conviene que nos detengamos un momento para realizar ciertas reflexiones sobre el desarrollo experimentado por la esbeltez de los alminares durante el siglo $X$. En efecto, el triunfante Estado islámico representado por el Califato omeya de al-Andalus supo aprovechar en su beneficio el papel de propaganda y exaltación dinástica que representaba la arquitectura monumental, y a ese papel se ajustaba perfectamente aquel tipo de construcción que era el alminar. Estas torres, al constituirse en el principal referente vertical de una ciudad musulmana eminentemente isótropa y horizontal, eran susceptibles de ser transformadas en hitos urbanos, verdaderos faros donde se reflejaba el poder de la autoridad, y que servían, a su vez, de modelos carismáticos para posteriores construcciones. Es por ello que todos los grandes alminares del Occidente islámico han estado vinculados siempre a poderosas dinastías que manifestaron sus momentos de esplendor a través de torres que rompían e innovaban en esbeltez y ornamento; así ocurrió con el gran alminar de 'Abd al-Rahman III de Córdoba, y, sobre todo, con la conocida tríada promovida por los califas almohades a finales del siglo XII: la Kutubiyya de Marrakech, la Hassan de Rabat y la Giralda hispalense.

29 Arroja esta cronología, de forma aproximada, F. HERNÁNDEZ GIMÉNEZ, Op. Cit., 1975, p. 208.

30 Sobre este alminar aún es válido el estudio de L. TORRES BALBÁS, "El alminar de la iglesia de San José y las construcciones de los ziríes granadinos", al-Andalus, VI, Madrid-Granada, 194I, pp. 429 y 430.

3I Consúltese, F. HERNÁNDEZ GIMÉNEZ, Op. Cit., 1975, p. I5।.

32 Ibidem, 1975, p. 109.

33 El alminar de la mezquita de los Andalusíes de Fez se construye en el año 345H/956; cita este dato H. TERRASSE, La mosquée des Andalous á Fés, París, 1950, p. 8. Mientras, la torre de la mezquita al-Qarawiyyin sería contemporánea a la anterior, según rezaba una lápida situada sobre su puerta; H. TERRASSE, La mosquée al-Qoraouiyin á Fés, París, 1968, p. 14. 
Sin embargo, en el caso de los alminares omeyas, y al margen de avances técnicos que, sencillamente, no se justifican en ese momento, hay que añadir una circunstancia que explicaría, aún más si cabe, ese espectacular desarrollo experimentado por éstos durante el siglo $X$. Nos estamos refiriendo a una de las principales causas de legitimación y rivalidad que afectaba en su marco de influencia al Califato cordobés: el Califato fatimí de Ifriqiya. Para estos shiíes, el alminar era un elemento superfluo, ya que la llamada a la oración debía realizarse desde las puertas de las mezquitas o sus tejados ${ }^{34}$. De ahí que pensemos que una de las causas que pudo justificar esta novedosa esbeltez tenga que ver directamente con la rivalidad existente con el poder fatimí, desarrollando una construcción monumental, proscrita por éste, a modo de instrumento propagandista; el Estado omeya lo comprendió perfectamente en el caso de los dos alminares de Fez citados con anterioridad, recién levantados tras ser recuperada esta ciudad por tropas afines a las autoridades de Córdoba.

Centrándonos en la fase primitiva de la torre de Medina Sidonia, llama la atención cómo lo conservado es susceptible de identificarse con ese esquema de alminar que hemos referido como tradicional en la arquitectura andalusí. Sin embargo, dicha obra fundacional se nos manifiesta hoy en día como incompleta, debido, quizás, al desmoche y ruina de la misma en un momento indeterminado; con posterioridad se recrecerá para cumplir con un nuevo cometido, aparentemente militar. Debido a esta circunstancia, poco podemos saber acerca de la altura total y esbeltez del primer cuerpo del alminar, así como de su terminación cimera, ya que no resta vestigio alguno de su linterna. De este modo, la máxima altura conservada, identificada por el tipo de fábrica (véase infra), y que corresponde al frente $\mathrm{SO}$, alcanza escasos $4.90 \mathrm{~m}$ sobre la actual rasante del terreno ${ }^{35}$.

Sin embargo, es a partir de la planta general de la torre de donde podemos extraer más datos que nos avalen una más que probable génesis islámica. En efecto, aquella presenta un contorno cuadrado, ligeramente trapezoide, esquema que se repite en un machón que sirve de elemento vertebral a la construcción en su primera etapa edilicia (Fig. 4). Las medidas máximas que arrojan ambos perímetros son de $3.63 \mathrm{~m}$ y $1.31 \mathrm{~m}$, respectivamente. Como hemos comentado con anterioridad, este esquema es el característico de los alminares andalusíes, sin que podamos precisar más en lo referente a posibles cronologías, dada la generalidad del mismo. Creemos que la comparación con las medidas en planta de otras torres no ofrece conclusiones infalibles, dada la inexistencia de cánones claramente identificables que nos permitan establecer diferencias geográficas y temporales. Félix Hernández llamó la atención sobre la existencia de un módulo en alminares de mezquitas secundarias que oscilaba en torno a 3.70 y $3.90 \mathrm{~m}^{36}$, sin embargo, y como ya ha apuntado acertadamente alguna investigación reciente ${ }^{37}$, la identificación de torres de oratorios modestos que no se ajustan a esta modulación, reafirma las dudas que dicha hipótesis plantea. Desde un punto de vista comparativo, las cotas en planta de la construcción de Medina Sidonia son similares

\footnotetext{
34 Refiere esta cuestión, P. GUICHARD, “Los Omeyas de Córdoba: las relaciones con el Magreb”, La Arquitectura del Islam Occidental, El Legado Andalusí-Ed. Lunwerg, Barcelona, 1995, p. 25. Sin ir más lejos, y por ejemplo, la gran mezquita de Mandiya, obra emblemática de los califas fatimíes en su gran fundación de Ifriqiya, prescinde de alminares que son sustituidos por curiosas aljibes a modo de torres; véase, F. MAHFOUDH, “La grande mosquee de Mandiya et son influence sur l'architecture médiévale ifriqiyenne", L'Égipte fatimide. Son art et son histoire. Actes du colloque organisé á Paris les 28, 29 et 30 mai 1998, París, 199, pp. 127 a 140.

35 La altura total del primer cuerpo de este alminar estaría comprendida, si tenemos en cuenta las cotas de su planta (3.63 m), así como las proporciones que parecen predominar en ese momento, entre 10.89 m (para una esbeltez de 1/3), I3.17 m (si adaptamos la proporción de I/3.63 del alminar de 'Abd al-Rahman III de Córdoba), o 14.52 m (según lo visto para los alminares omeyas de Fez).

36 Véase, F. HERNÁNDEZ GIMÉNEZ, Op. Cit., 1975, pp. 182 a 184.

37 Por ejemplo, para Córdoba se señalan los casos de las torres de las mezquitas de Santa Clara y El Fontanar, que sobrepasan los 4 m en planta; D. LUNA OSUNA, A. M. ZAMORANO ARENAS, Op. Cit., 1999, p. 157.
} 
a las estudiadas en las torres de San Juan de Córdoba $(3.70 \mathrm{~m})$ o San José de Granada $(3.85 \mathrm{~m})^{38}$, además de las deducidas para Santa María de la Granada de Niebla (unos $3.60 \mathrm{~m}$ ) y Almonaster la Real (alrededor de 3.67/3.85 m) ${ }^{39}$. Señalemos cómo todas estas torres, excepto la zirí de San José, serán de época omeya. Sin embargo, la presencia de otros alminares como el malagueño de Árchez, probablemente nazarí, con una medida de $3.50 \mathrm{~m}$, nos obliga a descartar cualquier asociación temporal en torno a las dimensiones en planta, ya que comprobamos cómo esta proporción se repite en ejemplares de muy diversas épocas. En cualquier caso, nuestra torre pertenece al grupo de alminares andalusíes más modestos, que oscila entre los $3.25 \mathrm{~m}$ de las torres de Cuatrovitas y Salares, y los $3.85 \mathrm{~m}$ correspondientes al alminar granadino de San José; casos como el de San Sebastián de Ronda, con 2.61 m de lado, se nos antojan excepcionales dado lo exigua de su estructura ${ }^{40}$.

En cuanto a las dimensiones del machón de la torre de Santiago del Camino, sus medidas de $1.31 \mathrm{~m}$ son similares, nuevamente, a las estudiadas en los alminares de Santa Clara de Córdoba y San José de Granada, con 1.40 m en ambos casos. Estableciendo una relación proporcional entre los perímetros de cuerpo inferiory machón, comprobamos cómo la mayor dimensión en planta del primero caso (4.45 m) hace que el esquema organizativo de la construcción que aquí presentamos sea más parecido al visto en el segundo de ellos (3.85 m).

\section{I .3. Organización interior}

El análisis de la estructura nuclear de la torre, nos obliga a centrarnos, en primer lugar, en la descripción de los accesos al interior de la misma. En su estado actual, a esta construcción se acomete desde el exterior a través de un vano adintelado, de $0.70 \mathrm{~m}$ de latitud, practicado en el frente $\mathrm{SO}$, junto al paramento $\mathrm{NO}$ del cuerpo anexo. Sin embargo, el análisis parietal de la fábrica de sillería donde está practicado nos convence acerca de su carácter posterior en relación con la primitiva fase edilicia de la torre. En efecto, dicho vano se habilitó mediante el desmonte y cercenado de varios sillares pertenecientes a siete hiladas consecutivas, de tal modo que el dintel resultante es de dudosa ortodoxia constructiva, al presentar una llaga en pleno centro. Así, resulta evidente que la entrada a la torre se resolvería en su origen a través de otro vano, de $0.79 \mathrm{~m}$ de ancho, hoy día cegado, que se localiza en el frente SE. Se organiza el mismo mediante un arco monolítico de medio punto, pieza pétrea de acarreo de indudable raigambre preislámica, dadas las características de su decoración (Lám. 4). Tomando como válida la hipotética organización planteada para esta mezquita de Medina Sidonia, vemos cómo este último acceso se adapta con rigor al que suele ser norma en los alminares andalusíes, abierto al patio, y orientado a la qibla, como es preferente en numerosas construcciones omeyas y taifas ${ }^{41}$. Aunque se sitúa de forma ligeramente excéntrica respecto al eje de la torre, dicho vano aparecería centrado en la fachada si consideramos el desaparecido muro de cierre NE del patio, que arrancaba desde dicho frente.

38 Véanse los datos aportados por el arquitecto L. TORRES BALBÁS, "Los alminares de las mezquitas hispanas", al-Andalus, X, MadridGranada, 1945, p. 392..

39 Obtenemos esta información en P. CRESSIER, S. ANGELÉ, "Velefique (Almería): un ejemplo de mezquita rural en al-Andalus”, Estudios de arqueología medieval en Almería, Almería, 1992, p. 257.

40 Entre estos casos excepcionales habría que situar al estudiado en la hacienda de Leirena, en Huévar (Sevilla), aún más pequeño que el referido de Ronda; consúltese, J. HERNÁNDEZ DÍAZ, A. SANCHO CORBACHO, F. COLLANTES DE TERÁN, Catálogo arqueológico y artístico de la provincia de Sevilla, Tomo IV, Sevilla, 1939, p. 283.

4 I En efecto, la situación del acceso enfrentado a la sala de oración aparece en los alminares de la primera mezquita mayor de Sevilla, en la aljama de Madinat al-Zahra', en el alminar de 'Abd al-Rahman III de la aljama de Córdoba (aunque completado con otro acceso hacia el norte), en San Juan y Santa Clara de Córdoba, en Santa María de la Granada en Niebla, y en San José de Granada; todos ellos, excepto el último caso, taifa, serán construcciones acometidas en periodo omeya. No obstante, también aparece en alminares más tardíos, de ahí que no podamos concluir de forma definitiva sobre esta cuestión; véase, por ejemplo, lo referido sobre la torre de Cuatrovitas en P. GURRIARÁN DAZA, Op. Cit., 2000, p. 172. 
Una vez franqueada la entrada aparece de forma inmediata, y a mano derecha, una meseta desde donde arrancan las idas de la escalera, ascendiendo siempre a izquierdas, y adoptando, de este modo, un sentido levógiro que caracterizará de forma indiscutible a nuestras torres de mezquitas. Las idas de la escalera conservadas de este alminar son bastante angostas, pues su latitud ronda los $67-68 \mathrm{~cm}$, aunque serán lo suficientemente amplias como para permitir el tránsito del almuédano en las horas preceptivas de oración (Fig. 4). Los dos primeros tramos, que son los únicos que restan sin reforma de la fase fundacional del alminar, se organizan cada uno mediante cuatro escalones de piedra de en torno a $30-35 \mathrm{~cm}$ de huella y $20-26 \mathrm{~cm}$ de tabica. Estos tramos descansarán en mesetas simples sin chiscarriclán. El tercer tramo conservado apoya sobre la única bóveda original conservada. Sin embargo, en su peldañeado encontramos algunas refacciones posteriores, como se aprecia en ciertas inclusiones de ladrillo, dado que se rehabilitó para poder dar acceso a la estancia superior asociada a una fase constructiva posterior. Para ello se trazaron más escalones, de modo que se pudiera salvar una considerable altura con un limitado desarrollo en planta, aunque se respetó, en la medida de lo posible, el intradós de la bóveda. De este modo, en su estado actual, se constituye este tercer y último tramo mediante cinco escalones, que forman el trasdós de la citada bóveda islámica, y que comunican con otros cuatro que acometen al nivel de la estancia cimera tras girar progresivamente noventa grados.

Respecto a la forma de resolver el aboyedamiento interior de la torre, diferenciaremos dos tipos de soluciones que responderán cada una a un momento de uso distinto (Fig. 5). En primer lugar, aparece un tipo de bóveda escalonada, formada por lajas y losas pétreas, que sirve de base al peldañeado del tercer tramo de la escalera ya citado (Lám. 5). Por otra parte, y a continuación de aquella, encontramos tres bóvedas de medio cañón y directriz horizontal, dispuestas a montacaballo, que cubren sucesivamente el pasillo de acceso a la torre y los dos primeros tramos de la escalera (Lám. 6). La primera de las bóvedas citadas, de la cual sólo se conserva un tramo, pensamos que forma parte de la obra primitiva de la torre, es decir, de la correspondiente a su uso como alminar Esta forma de resolver escalonadamente la cubrición de las idas de la escalera, configurando, a su vez, el peldañeado sobre su trasdós, está ampliamente documentada en el mundo andalusí. Sin ir más lejos, y como ha sucedido con otros aspectos analizados, los paralelos más próximos los encontramos en las torres de Santa Clara de Córdoba y San José de Granada ${ }^{42}$, con idéntico esquema estructural. Esta solución, lógica y de gran racionalidad constructiva, pensamos que es una traslación sintética y muy simplificada de la que se empleó como cubrición para las idas de las escaleras del alminar de 'Abd al-Rahman III en la aljama cordobesa, organizada, en su caso, mediante falsas bóvedas escalonadas que cobijaban otras aparentes sobre cornisas ${ }^{43}$. Aunque algunos alminares de machón cilíndrico cubrían sus escaleras con losas dispuestas de forma helicoidal ${ }^{44}$, tal debió ser la influencia ejercida por las novedosas bóvedas del gran alminar cordobés, que su esquema estructural, desprovisto de todo elemento superfluo, fue adoptado casi de inmediato en varias secuelas modestas coincidiendo con el triunfo del machón cuadrado. Con posterioridad se abandonaría este tipo principalmente por el que recurre a bóvedas de medio cañón, sobre todo de directriz horizontal, solución que, aunque predominará a partir de lo almohade, ya era de sobra conocida desde el siglo IX en el Islam al-Aqsa, como vemos en el alminar de la gran mezquita de Qairawan.

\footnotetext{
42 Respecto al primero de estos alminares, consúltese, nuevamente, F. HERNÁNDEZ GIMÉNEZ, Op. Cit., 1975, p. 207. Referente a la torre de San José, L. TORRES BALBÁS, Op. Cit., 1941, p. 429..

43 Consúltese la completa descripción que nos proporciona de estas bóvedas F. HERNÁNDEZ GIMÉNEZ, Op. Cit., 1975, pp. 50 a 59 , Figs. 9 y 10.

44 Así sucede con las losas que forman la escalera del alminar de la aljama de Ibn 'Adabbas de Sevilla, Ibidem, 1975, p. 160.
} 
En el caso que nos ocupa conviene que realicemos una serie de puntualizaciones en lo referente a esta bóveda escalonada. En primer lugar es preciso que apuntemos lo tosco y poco depurado de su trazado, con numerosos apaños y refacciones donde se aprecian sustracciones de piezas e inclusiones puntuales de ladrillo. Además, hemos de tener en cuenta que, salvo el primer peldaño del tercer tramo de la escalera, que apoya en la bóveda, todos los demás que le siguen presentan ciertos arreglos relacionados con el posterior aumento del número de escalones en el tramo, fijado en cuatro en los dos anteriores. Además, existen algunos detalles que separan estas bóvedas de la torre de Medina Sidonia de las vistas en sus congéneres de Santa Clara y San José. Uno es que, mientras que en estos dos alminares los escalones se forman mediante simples piezas monolíticas, que en la torre cordobesa son, además, los mismos sillares utilizados para las fábricas de los muros, en nuestro caso, la solución empleada en cada escalón pasa por la acumulación de un conjunto de losas, más o menos aparejadas. Este proceder edilicio permitirá luego la reforma del peldañeado primitivo sin alterar excesivamente el intradós de la citada bóveda. Por otra parte, refiramos, dado su interés, cómo esta bóveda escalonada apoya en puntos determinados en una serie de piezas dispuestas en ménsula que empotran sus testas en el muro perimetral de la torre y en el machón; esta circunstancia, y el hecho de que las losas que forman dicha cubrición penetren, así mismo, en ambos elementos, relacionan a la bóveda, machón y muro exterior de sillería con un mismo momento constructivo, esto es, con la fase fundacional de la torre. Desde luego, esta solución consistente en apoyar las losas de la bóveda en ménsulas no encuentra parangón alguno en alminares, y sí nos transmite un lejano parentesco con otras identificadas en obras militares omeyas de al-Andalus, tal es el caso de las falsas bóvedas estudiadas en las torres del Andador de Albarracín, en algunas del sistema defensivo de Calatayud, y en un postigo de la fortaleza califal de Gormaz, aunque todas ellas sin escalonar ${ }^{45}$.

Comentario aparte merecen las bóvedas de medio cañón, de las cuales hablaremos en detalle al tratar de la torre como obra defensiva, pues, efectivamente, parecen responder a la gran reforma que sufrió esta construcción para adaptarse a su nuevo cometido. Ello se justifica cuando se comprueba cómo la primera de ellas se traza a continuación de la escalonada conservada, justo por encima del máximo nivel de sillería señalado en los muros exteriores de la torre. Dado que todas estas bóvedas de medio cañón se construyen a partir de esa cota que parece delimitar la primera fase de la construcción, a la cual amortizan, y dado que, además, traban con la fábrica de mampuestos y ripios que se superpone a la de sillares, es lógico que establezcamos un mismo momento constructivo para recrecido y bóvedas de medio cañón, posterior por tanto al fundacional. Esa fase responderá a la segunda etapa edilicia de la torre como reducto militar. Dichas bóvedas apoyan en el machón central, aunque siempre por encima del nivel marcado por la sillería del perímetro de la construcción. De este modo, el machón habría sido reformado en lo que resta de alzado para permitir el apoyo de las nuevas bóvedas y de los escalones que se añaden en el tercer tramo de la escalera.

\section{I.4. Algunas consideraciones sobre huecos y decoración}

En lo conservado de obra islámica no encontramos vestigio alguno de ornamentación cuyo origen sea coetáneo al primer momento de uso de la torre. Todo lo más que podemos señalar está relacionado con la presencia del arco monolítico que cobijaba el acceso al alminar, el cual es una pieza de acarreo depredada, posiblemente, de alguna importante construcción preislámica de la vecina Medina Sidonia. Hemos de tener en cuenta que no es extraño el empleo de material de acarreo en

\footnotetext{
45 Véase el análisis de A. ALMAGRO GORBEA, "Las torres beréberes de la Marca Media. Aportaciones a su estudio", Cuadernos de la Alhambra, No 12, Granada, 1976, pp. 301 a 303, Hg. 9, Lám. V.
} 
puertas de alminares del Islam occidental, como ocurre, por ejemplo, en el de la gran mezquita de Qairawan, donde se recurre a elementos de origen romano ${ }^{46}$. Sin ir más lejos, el cuerpo bajo de la torre de San Salvador de Toledo, identificado como alminar, ve recorrido su perímetro por una cenefa decorada de evidente ascendente visigodo ${ }^{47}$. Además, la utilización de piezas preislámicas procedentes de expolio es habitual en las mezquitas andalusíes desde un primer momento, tal y como se atestigua ya en las dos primeras fases constructivas de la mezquita de Córdoba, y luego en diversos oratorios como Almonaster la Real, Archidona o, incluso, en el mismo basamento de la Giralda.

Conviene recordar cómo la carga de exorno en los alminares de al-Andalus solía disponerse siempre en la mitad superior del primer cuerpo, cuando estos son de proporción dupla, o a partir del primer tercio cuando la esbeltez alcanzaba una relación de 1/3 o más. En un primer momento, el ornato estará asociado casi con exclusividad a los huecos o bíforas que se practicaban en los paramentos para iluminar unos interiores, que, por otra parte, solían ser bastante sombríos. En dichos vanos se volcaba todo el léxico edilicio que triunfaba en cada época, de ahí que suelan ser unos buenos fósiles directores para aproximar cronologías. Con posterioridad, y ya en el siglo $X$, los alminares hispanomusulmanes coronarán sus cañas con arquerías ciegas, enriqueciendo progresivamente sus epidermis, hasta culminar, por último, con la explosión de barroquismo que supondría la sebka almohade. Sin embargo, los ricos conjuntos decorativos que se estiman dispusieron los paramentos de los alminares de 'Abd al-Rahman III en Córdoba y de la aljama de Zaragoza, de los siglos $X$ y $X I$ respectivamente, sugieren que, al menos los alminares próceres, solían cuidar su terminación tectónica con un cierto esmero ${ }^{48}$.

A partir de lo expuesto, se comprende que, dado lo poco conservado de este alminar de Medina Sidonia (con $4.90 \mathrm{~m}$ de alzado máximo para $3.63 \mathrm{~m}$ de base), nos encontremos justo en ese límite a partir del cual es posible la presencia de alguna ventana de carácter principal. Sin embargo, el estudio de los paramentos de la torre no aporta ningún vestigio de apertura o vano. Ello se debe a que este tramo constituía aún el basamento sobrio y sin ornato de la torre, sobre el cual ya aparecerían los huecos de iluminación y cualquier tratamiento ornamental, como, por ejemplo, una hipotética arquería ciega. Los únicos elementos señalados en los muros islámicos de esta construcción son un par de pequeños huecos, a modo de saeteras, practicados a una misma altura en el frente NE, en torno a dos metros sobre la rasante del terreno. Estos discretos tragaluces, uno de 30 $\times 18 \mathrm{~cm}$ y otro de $32 \times 14 \mathrm{~cm}$, iluminarían los dos primeros tramos de la escalera sin romper la estricta uniformidad exterior que reinaba en la base del alminar. Señalemos cómo dichos huecos se habilitarían sin más esfuerzo que el derivado de eliminar en el muro un sillar a tizón, cuya medida de testa se aproxima en esta construcción a las cotas referidas. Encontramos una solución constructiva idéntica en las torres de Santa Clara de Córdoba y de San José de Granada ${ }^{49}$ no obstante, el replanteo parietal de sus tragaluces sigue el desarrollo de las idas de la escalera, de ahí que aparezcan escalonados y no a nivel. Similar esquema pareado vemos en unas saeteras situadas en el frente $\mathrm{SO}$ del alminar almohade de Cuatrovitas.

\footnotetext{
46 Cita esta cuestión K. A. C. CRESWELL, Op. Cit., 1979, p. 143.

47 Apunta en este sentido lo referido por B. PAVÓN MALDONADO, Arte toledano: islámico y mudéjar, Madrid, 1988, p. 55, y por L. TORRES BALBÁS, Op. Cit., 1957, p. 615 .

48 Véase para el alminar cordobés, F. HERNÁNDEZ GIMÉNEZ, Op. Cit., 1975, pp. 80 y 81, mientras que para la torre de Zaragoza, A. ALMAGRO GORBEA, Op. Cit., 1993, pp. 333 a 339, Fig. I.

49 Refiere esta circunstancia para la torre de Santa Clara, F. HERNÁNDEZ GIMÉNEZ, Op. Cit., 1975, p. 208, Fig. 45.
} 


\subsection{Análisis constructivo}

Hasta ahora hemos estudiado cómo la torre en cuestión se adapta de forma precisa y coherente con el esquema tipológico y morfológico que predomina en los alminares andalusíes. El estudio constructivo, sobre todo eñ lo referente a la resolución y formalización de sus paramentos, no aporta apenas más información en lo referente al análisis del tipo, casi agotado antes, sin embargo, nos ayuda a aproximar el origen de la construcción dadas sus características. En última instancia, y para dejar zanjada la cuestión temporal, se deberá contrastar la cronología obtenida en el análisis edilicio con el tipo dominante en ese momento (véase el apartado "Secuencia de evolución diacrónica").

Los muros conservados del alminar se resuelven de forma integra mediante fábrica de sillería; sobre ella asienta, recreciéndola, otra de mampostería y ripio con las esquinas solucionadas a base de un encadenado de sillarejo (Figs. 6 y 7). Por lo que respecta a la obra original, cabe apuntar cómo la sillería se organiza sistemáticamente según el aparejo conocido como de "soga y tizón". En este caso, se observa la combinación de uno a tres tizones con simples sogas de muy diversa factura; sólo en un punto concreto de la cara NE se aprecian cinco tizones consecutivos. No obstante, debemos señalar el escaso rigor modular y la poca regularidad de esta fábrica. En el caso de buscar algún tipo de canon constructivo, éste aparecería en cada hilada considerada de forma aislada, al resolverse siguiendo una misma altura y una sucesión más o menos regular de sogas y tizones. Sin embargo, el estudio comparativo de las distintas hiladas entre sí nos muestra la variación indiscriminada de las alturas (entre 20 y $40 \mathrm{~cm}$ ) y de la formalización del aparejo. Es habitual el empleo puntual de sillares reaprovechados, sobre todo de gran formato, como observamos en las esquinas septentrional y occidental del basamento de la torre; además, no es extraña la presencia de engatillados en alguno de ellos. Parece que la irregularidad de las hiladas inferiores se debe a la necesidad de adaptar sus alturas a esas grandes piezas que constituyen las esquinas, de modo que estos sillares son el principal condicionante para la modulación de las hiladas dispuestas entre ellos. Las escasas filas de sillares conservadas por encima organizan sus alturas de forma más coherente y regular al no depender de dichas piezas de acarreo.

Predominan en esta fábrica sillares labrados ex profeso siguiendo una proporción muy esbelta y alargada, con dimensiones generales bastante discretas. Refiramos cómo las medidas de las testas oscilan entre los I I y los $20 \mathrm{~cm}$ (con predominio de $14-15 \mathrm{~cm}$ ) y las de las sogas entre los 50 y los $64 \mathrm{~cm}$ (con mayoría de las que arrojan 56-58 cm). Los paramentos exteriores de la torre están aparejados al completo con estos sillares, y así, cada tizón atraviesa completamente el muro asomando sus testas por ambas caras; en el caso de las sogas, éstas se juntan en número de tres o cuatro para macizar todo el grosor de la fábrica. Si tenemos en cuenta que los muros exteriores arrojan una latitud comprendida entre los $41 \mathrm{~cm}$ del frente $\mathrm{SO}$ y los $46 \mathrm{~cm}$ del NE, se comprende cómo los sillares dispuestos a tizón deben trabajarse más cortos que los que se colocan a soga. Esta circunstancia resulta sorprendente pues obliga al corte de dos tipos de piezas según su colocación, con el evidente perjuicio logístico y de organización del trabajo que conlleva; no obstante, esta particularidad se identifica en otros alminares de cantería, tal es el caso de Santa Clara de Córdoba. Por otra parte, el débil espesor de los muros nos obliga a descartar cualquier propósito defensivo para la obra primitiva, corroborando así el uso sacro de la misma.

Los sillares de la torre, tanto de arenisca del Aljibe como de conglomerado ostionero, están tomados mediante un mortero de cal caracterizado por su excesiva proporción caliza en relación con el árido. Esta circunstancia hace que el aglomerante sea blancuzco y de una textura general muy fina. Las juntas de la fábrica se organizan mediante llagas y tendeles muy sutiles y delgados, con escasos $0.5 \mathrm{~cm}$ de espesor, aunque en ocasiones identificamos una ligera rebaba. No obstante, el deterioro de la piedra ha ocasionado que los sillares hayan debido de ser calzados puntualmente, $y$ con posterioridad, mediante un rejuntado a base de fragmentos pétreos y de ladrillo. Poco podemos precisar 
sobre los revestimientos, de los cuales restan escasos testimonios. En los frentes NE y NO se conservan restos de un enlucido superficial cuyo origen no sabemos si se corresponde con la fase islámica de la torre, aunque es más probable que esté asociado a las obras de recrecimiento u otras posteriores, dada la similitud que presenta con los revestimientos que encontramos en las zonas cimeras.

En el interior de la torre se identifica un cambio de fábrica con respecto a lo visto en los muros perimetrales, tanto en el machón central como en la bóveda escalonada ya citada. En efecto, la bóveda está resuelta con simples lajas y losas de piedra apoyadas en sillares en voladizo. Por su parte, el machón vertebral de la torre no se apareja en cantería como sucede en otros alminares similares, sino que para este elemento se opta por una fábrica de mampostería poco cuidada y con inclusiones puntuales de ladrillo. Esta solución constructiva evidencia un intento de economizar los trabajos, destinando la sillería a los muros perimetrales y recurriendo a una fábrica menos costosa, aunque de contrastada solvencia estructural, para erigir el machón. En la actualidad este elemento aparece recubierto por una fina capa de pintura. La cara interior de los muros, por su parte, están descarnados y con el aparejo de sillería perfectamente visible.

El estudio de la torre revela cómo su fase original se promovió según un único impulso edilicio. La similitud tecnológica y formal que encontramos en las fábricas, y la resolución de muros, bóveda escalonada y machón como una unidad constructiva, apuntan en ese sentido. El posterior recrecido de la primera obra se distingue perfectamente en los paramentos exteriores dada la diferencia de aparejos, y además, coincidirá con el empleo de una nueva solución para resolver el abovedamiento interior. De este modo, la rotunda y precisa ruptura entre ambas fases apunta en el sentido de que la torre primitiva se encontraba arruinada (io tal vez inconclusa?) en el momento de su rehabilitación; además, hemos de tener en cuenta que si hubiera sido desmochada para tal fin, sus sillares hubieran sido reaprovechados masivamente para las nuevas fábricas, y ese no es el caso.

Tras esta breve exposición de las características constructivas generales de la torre, procederemos a analizar con mayor rigor los datos que éstas nos aportan. El elemento que, quizás, nos proporcione mayor información, dada su peculiaridad, sea el aparejo de los paramentos exteriores. En efecto, la fábrica de sillería organizada mediante el uso alterno de sogas y varios tizones nos remite de forma directa al mundo andalusí, y más concretamente, debido a uso sistemático, al Califato omeya (Lám. 7). Queda descartado cualquier otro origen para el aparejo de esta torre al no existir tradición en la zona tras la conquista castellana, y no ser habitual en lo preislámico. El análisis comparativo con otras edificaciones así construidas nos puede ayudar a precisar la cronología; para ello no sólo recurriremos a otras obras religiosas, sino que, incluso, será muy útil su identificación con ciertas estructuras defensivas o civiles dado el carácter homogéneo y versátil de este tipo de fábrica. Además, hemos de tener en cuenta que el empleo de sogas y tizones, exhaustivo en toda la producción arquitectónica omeya, evolucionará de forma clara en su formalización desde las primeras construcciones estudiadas del siglo VIII hasta las últimas amiríes e incluso taifas ${ }^{50}$. Esta circunstancia será evidente sobre todo en la metrópoli cordobesa y en sus grandes obras oficiales.

A partir de las estructuras de Madinat alZahra empieza a ser común el aparejo que combina una soga con dos o tres tizones ${ }^{51}$, procedimiento edilicio que llevará asociada una mayor esbeltez de los sillares y un evidente

50 Sucede así con algunas construcciones de la taifa granadina de los ziríes; véase el estudio, aún valido, de L. TORRES BALBÁS, Op. Cit., 1941, pp. 422 a 446.

5I El estudio de Félix Hernández sobre el gran alminar de la aljama cordobesa no es sólo un magnífico estudio sobre el alminar andalusí, sino que sirve como útil compendio de construcción califal; así, se cita esta cuestión referida a la cronología de los aparejos de soga y dos y tres tizones en F. HERNÁNDEZ GIMÉNÉZ, Op. Cit,, 1975, p. 146. 
alejamiento de las testas cuadradas que predominaban en el Emirato. Algunos de los sillares de la ciudad áulica cordobesa arrojarán así Una medida de 70-120 cm de largo, 44-35 cm de alto, y 20-25 cm de ancho ${ }^{52}$. También se identifica este aparejo de forma llamativa en los muros de la parte del patio que amplía 'Abd al-Rahman III en la aljama de Córdoba, y no así en el nuevo alminar. El proceso de estilización de las testas de los sillares alcanzará su punto culminante en periodo amirí, y así, en la última ampliación del gran templo cordobés se estudiarán piezas con unas medidas de $108-120 \mathrm{~cm}$ de largo, 35 de alto, y 16-20 cm de grueso ${ }^{53}$. En el alminar de Santa Clara de esta misma ciudad, edificado tal vez a finales del siglo $X$, el aparejo es de soga y dos $y$ tres tizones, con cotas de 96- $104 \mathrm{~cm}$ de largo, 36-40 de alto y $20 \mathrm{~cm}$ de ancho; además, en esta torre la construcción de los muros será muy similar al caso que nos ocupa ${ }^{54}$. Otra obra parecida en su esquema edilicio es la también referida torre de San José de Granada, aunque en este caso, los sillares (65 $\times 40 \times 10 \mathrm{~cm}$ ) se dispondrán hasta en cinco tizones consecutivo ${ }^{55}$; será este alminar un caso de pervivencia de formas constructivas califales en periodo taifa.
Aparejos similares se identifican en otras obras sacras califales, como la mezquita mayor de Almería ${ }^{56}$, y, sobre todo, en numerosas construcciones defensivas. No obstante, apuntaremos cómo en este último caso las precisiones cronológicas que se realicen serán a menudo vagas al no disponer apenas de testimonios cronísticos o epigráficos que las precisen; además, la evolución de los aparejos no será idéntica e inmediata a la vista en las construcciones civiles cordobesas. Uno de los ejemplos más fiables y cercanos lo encontramos en el castillo de Tarifa, mandado construir por el califa 'Abd al-Rahman III en el año 349H/960 según reza su lápida fundacional. El aparejo de sus muros, muy regular, será parecido al visto en la torre de Medina Sidonia, así como las medidas de sus sillares $(70-90 \mathrm{~cm}$ de alto, $30-35 \mathrm{~cm}$ de alto, 13-20 cm de ancho) y el tipo de piedra empleada ${ }^{57}$. Fábricas similares en su organización y proporciones las encontramos en otros recintos militares fechados durante el Califato, tal es el caso, por ejemplo, de las alcazabas de Tánger ${ }^{58}$ y Almería ${ }^{59}$, o los husun de Priego de Córdoba ${ }^{60}$ y de Poley ${ }^{61}$.

52 Recuérdese que las obras de Madinat al-Zahra' se comienzan en 325H/936; referente a las medidas de los sillares, consúltese S. LÓPEZ-CUERVO, Medina Az-Zahra. Ingeniería y formas, Ministerio de Obras Públicas y Urbanismo, Madrid, 1983, p. 53.

53 Predomina en este aparejo un sillar a soga con dos a cinco tizones, véase, L. TORRES BALBÁS, Op. Cit., 1957, p. 574.

54 Véase lo referido en F. HERNÁNDEZ GIMÉNEZ, Op. Cit., 1975, pp. 205 y 206, Fig. 46. Otra circunstancia que conviene destacar es cómo en esta construcción los sillares dispuestos a tizón, que atraviesan el muro de $6 \mathrm{l} \mathrm{cm}$ de espesor, deben tallarse más cortos que las sogas que arrojan casi un metro de longitud, de forma similar a lo estudiado en la torre de Medina Sidonia.

55 L.TORRES BALBÁS, Op. Cit., I 941 , p. 429.

56 Consúltese el estudio de L.TORRES BALBÁS, “La mezquita mayor de Almería”, al-Andalus, XVIII, Madrid-Granada, 1953, p. 4I8. Este arquitecto, que fecha este edificio a finales del siglo X, refiere para los sillares conservados unas medidas de $95 \mathrm{~cm}$ de largo, $35 \mathrm{~cm}$ de alto y $15 \mathrm{~cm}$ de ancho. Véase también, dado su interés, la fotogrametría que de estos aparejos realiza A. ALMAGRO GORBEA, E.E.A., C.S.I.C., "Almería, Iglesia de San Juan, alzado del muro de la qibla de la Aljama de la ciudad", en Arquitectura en al- Andalus. Documentos para el siglo XXI, Barcelona, 1995, pp. 228 y 229.

57 Véase lo estudiado en P. GURRIARÁN DAZA, "Arquitectura y técnicas constructivas califales en el castillo de Tarifa", Actas de las VI Jornadas de Historia del Campo de Gibraltar (Gibraltar, 2000). Almoraima, N²5, Algeciras, 200 I, pp. 174 a 178.

58 Las medidas de los sillares estudiados en la alcazaba tangerina ofrecen unas cotas de $99.5 \times 30 \times 14-21 \mathrm{~cm}$. Cita esta cuestión, A. ELBOUDJAY, "La muraille califale de la Qasba de Tanger", Caetaria, N³, Algeciras, 2000, p. 153.

59 Los sillares arrojan unas medidas de $61 \times 31 \times 12-14 \mathrm{~cm}$. Véase, L. CARA BARRIONUEVO, La alcazaba de Almería en época califal. Aproximación a su conocimiento arqueológico, Almería, 1990, p. 21.

60 Las cotas de estas piezas rondan los 45-60 × 29-31 × 19 cm. Consúltese, R. CARMONA AVILA et alii, "Excavaciones arqueológicas en el Castillo de Priego. Informe de la intervención arqueológica de urgencia de 1998", Antiqvitas, No I0, Priego de Córdoba, 1999, p. 186.

6I La proporción de los sillares estudiados se ajustan a una medida de 55-60 × 30 × 14 cm; A. LEÓN MUÑOZ, "Testimonios arqueológicos del Hisn de Poley en época califal (Aguilar del Campo)", Actas I Congreso Internacional Fortificaciones en al-Andalus (Algeciras, noviembre-diciembre, 1996), Algeciras, 1998, p. 373. 
En cualquier caso, y sin querer extendernos más en esta cuestión, lo que nos interesa resaltar para este alminar es su identificación con una forma constructiva muy particular que se corresponde claramente con una etapa histórica concreta. Aunque el aparejo de esta torre sea bastante torpe e irregular en relación con lo más granado de la construcción oficial cordobesa, su similitud métrica y formal con lo estudiado en el Califato nos obliga a fechar estos muros durante dicho periodo. Otro aspecto, como es el empleo de morteros con mucha pureza de cal, también será característico del momento del cual hablamos ${ }^{62}$. Con respecto al machón de la torre, cabe apuntar cómo el recurso a la mampostería no es común en aquellos alminares que solucionan la estructura de sus muros mediante sillería, en cuyo caso se suele emplear también esta fábrica para el citado elemento vertebral. Este detalle, junto con la poca exquisitez del aparejo de sillería, apuntan hacia una obra modesta en recursos y con capacidad técnica limitada, aunque, por otra parte, el esquema general de la fábrica y la similitud edilicia con otros alminares califales (sobre todo con el de Santa Clara) denotarán la inmediata difusión de formas constructivas de la metrópoli hacia simples obras provincianas, lo cual da una idea de la "universalidad" alcanzada por la arquitectura califal en al-Andalus.

\section{LA TORRE COMO OBRA MILITAR}

\section{I. Análisis arquitectónico y mor- fológico}

La torre de la ermita de Santiago del Camino presenta algunos rasgos morfológicos que permiten clasificarla como obra militar en algún momento de su dilatada existencia. No obstante, para tratar este capítulo debe abordarse su estudio en relación con el cuerpo que se le adosa por su fachada SE. Las almenas que coronan la torre, las cuatro aspilleras abiertas en el pretil del terrado y un par de ménsulas, posibles restos de una ladronera en su cara $\mathrm{NO}$, sugieren un reaprovechamiento del edificio como enclave defensivo posterior a su uso religioso islámico. De los elementos citados, ninguno presenta características individualizadoras que permitiesen» atribuir alguna cronología absoluta a dicha etapa de uso militar, según se precisa a continuación. En cualquier caso, resulta fundamental apuntar que todos se localizan en la parte alta del edificio, identificada como recrecimiento del alminar arruinado, en momento y circunstancias que trataremos de establecer posteriormente.

El pretil de la azotea, a diferencia del cuerpo de menor altura que tiene anexo, dispone de singular merlatura para lo usual en esta zona (Lám. 8). Presenta tres merlones por fachada, siendo comunes los de las esquinas para cada dos caras contiguas. Están construidos con mampostería y fragmentos de ladrillo reaprovechados. Originalmente de igual anchura que altura, como se comprueba por la terminación de ladrillos que los remataba, fueron recrecidos piramidalmente en algún momento inmediato al de la construcción del edificio. Así lo sugieren los materiales empleados $y$, especialmente, la homogeneidad de la argamasa empleada en las dos fases edilicias de la merlatura. Resulta difícil en extremo interpretar el modelo seguido para completar dicho remate, cuyos planos inclinados que configuran la estructura apuntada de los merlones presentan una ligera curvatura que sólo cuenta con paralelos conocidos en edificios aglabíes de Ifriqiya, de los siglos VIII y IX, impropios en al-Andalus. Desde un enfoque práctico, pueden ser relacionados con un recrecimiento en altura que mejorase la protección de los ocupantes del terrado, toda vez que las magnitudes originales de los merlones prestaban una escasa defensa. Los merlones centrales de cada fachada tienen una anchura media de $0.85 \mathrm{~m}$ y una altura respecto al terrado que ronda los $2 \mathrm{~m}$. Las

62 Cita este aglomerante como característico del periodo omeya, al referirse al alminar cordobés de San Juan, F. HERNÁNDEZ GIMÉNEZ, Op. Cit., 1975, pp. 136 y |42. Aparece también, entre otras muchas construcciones, en lo primitivo del castillo de Tarifa; P. GURRIARÁN DAZA, Op. Cit., 200 I, p. 178. 
caras internas de los vanos entre merlones aparecen enfoscadas y presentan improntas verticales sobre la argamasa, lo que denota un tratamiento realizado cuando se aplicó el revestimiento y aún estaba fresco. Esta circunstancia descarta cualquier propósito constructivo en dichas marcas. Como hipótesis de trabajo y, dada su situación, pudieran relacionarse con algún fin práctico, como marcos para artilugios de madera aspillerados que harían notablemente más eficaz el uso defensivo del terrado. Ocurre que los merlones esquineros protegen una porción tan reducida de cada uno de los frentes de la azotea, que resultarían escasamente útiles de no disponer de otros dispositivos adicionales. Es más, dada su pequeña superficie y la escasa elevación del edificio, cualquier tirador oculto tras los merlones de una cara de la torre podría ser fácilmente alcanzado por proyectiles procedentes de la cara opuesta. Como hemos señalado, estos datos sugieren elementos de madera con saeteras o, menos probablemente, manteletes practicables, capaces de solventar tales inconvenientes, convirtiendo este terrado en una superficie de combate mínimamente eficaz.

El segundo tipo de elementos conservados y relativos al uso militar de la torre consiste en las cuatro saeteras abiertas en el pretil de la azotea, a nivel del suelo, Se trata de aspilleras verticales simples, encuadradas por sillarejos de piedra, que carecen de significación particular alguna. Su disposición en las cuatro fachadas del edificio sugieren que éste, en época de inseguridad, estuviera exento por completo, lo que exige posponer la datación del cuerpo mudéjar a otra fase constructiva posterior cuando se empieza a colmatar de edificaciones el antiguo patio de la mezquita. Dado que la habitación de la torre pudo haber sufrido problemas de humedades originados en su cubierta, se. pro- cedió a inclinar el suelo del terrado hacia la cara NE añadiéndole una gruesa torta de mampuestos y argamasa rica en cal. Esta reforma ha provocado que algunas aspilleras quedaran parcialmente cegadas, presuntamente por poder prescindirse de su utilidad militar. La orientada al NO sirve desde entonces como desagüe de la azotea, lo que se evidencia por el recubrimiento de liquen vivo de parte de sus paramentos exteriores.

Por último, la fachada noroccidental de la torre conserva, a cinco metros de altura, dos ménsulas monolíticas simples y desiguales en tamaño. Pudieron soportar una ladronera de escaso vuelo, que tendría acceso por un esbelto vano abierto en la estancia superior de la torre. Este tipo de elemento defensivo tuvo amplia difusión desde la Antigüedad hasta bien entrada la Edad Moderna, y aunque aparecieron en la Europa cristiana hacia finales del siglo XIII, en España es dudoso su empleo antes del siglo XIV ${ }^{63}$. No es común en la poliorcética andalusí, si bien pudiera existir algún ejemplo de periodo nazarí, como vemos en la torre- puerta de la villa fórtificada de Moclín. En nuestro caso, la ladronera habría defendido el frente más expuesto de la torre, que no podía ser flanqueado desde ninguna otra construcción vecina. No debe descartarse, no obstante, un improbable uso como balcón, más propio de un edificio con finalidad residencial que parece reñida con el estrecho espacio útil de la construcción. Actualmente cegado dicho vano de la fachada NO por una citara de ladrillo, presenta jambaje de sillería y se cubre con arco de medio punto.

Desde una perspectiva estrictamente poliorcética, la ventana que presenta la fachada SO de la torre, a la altura de la estancia superior, podría haber tenido cierta función defensiva

\footnotetext{
63 Este dato se concreta en la torre de El Carpio por epigrafía de 1325, según L. de MORA FIGUEROA, Glosario de Arquitectura Defensiva Medieval, Cádiz, 1994, p. 123. Otras obras tempranas que presentan el mismo dispositivo para la defensa de sus vanos siguen sujetas a cierta indefinición cronológica. Es el caso de la torre de El Cambrón en Almuñécar, Granada (C. TORRES DELGADO, Descripción de las defensas de la Costa del Reino de Granada (1830). Anejo de Cuadernos de Estudios Medievales, Vol. I, Granada, I983, p. 6) o la de Botafuegos en Los Barrios, Cádiz (Á. J. SÁEZ RODRÍGUEZ, Almenaras en el estrecho de Gibraltar. Las torres de la costa de la Comandancia General del Campo de Gibraltar, Instituto de Estudios Campogibraltareños, Vol. I6, Algeciras, 200 I, p. 259 y ss.).
} 
llegado el caso. En rigor se trata de un vano de iluminación de la habitación de la torre, encuadrado por sillarejos y cubierto con arco de medio punto. Tal finalidad resulta contradictoria en una estancia pequeña que además cuenta, actualmente, con los huecos de acceso por la escalera desde la planta baja, salida al terrado de la torre, comunicación con la azotea del edificio anexo y vano de la ladronera. Todo hace indicar que en su mayor parte corresponden al momento principal de reconstrucción y fortificación de la torre, hacia los siglos XIII-XIV.

Las características del añadido cuerpo mudéjar sugieren que su construcción debió realizarse en fecha poco posterior a la fortificación y reforma del alminar. Se trata de una obra de potentes muros de mampostería calzada puntualmente con ladrillo, de 1.30 metros de espesor ligeramente ataludados, y construidos principalmente de mampostería enripiada con ladrillo, con piedras de mayor tamaño en las esquinas. Se reconocen tres momentos constructivos diferentes y abundantes refacciones puntuales, lo que dificulta especialmente la lectura de ĺos paramentos. Alberga una única estancia cubierta con bóveda vaída. En este momento el acceso a la torre siguió realizándose por su puerta original, abierta en su cara $\mathrm{SE}$, según hemos señalado. Sólo con la definitiva retirada de la frontera granadino-meriní, la pacificación general del reino y la conexión del doble edificio con el oratorio cristiano, pudo transformarse por completo el sistema de acceso: la puerta primitiva fue cegada y, en su lugar, abierta la de la fachada sudoccidental de la torre, tal y como hoy puede contemplarse. El cuerpo mudéjar de dicho conjunto cuenta en la actualidad con tres vanos abiertos en sus recios muros. El más moderno es el que se abre en su cara SO, una vez inutilizado el original al habérsele adosado la sacristía del nuevo templo cristiano en el espacio del antiguo sahn. Esta puerta original, situada en la fachada sudeste del edificio, se sitúa enfrente del que permitía la comunicación con la torre, hoy cegado. La zona que rodea la puerta que ahora lo comunica con el exterior se realizó al estilo de la parte superior de la torre, con mampostería sumamente irregular y sin apenas ladrillo. No quedan restos de elementos propiamente militares, a excepción de la potencia de los muros y cierto aire de fortificación de la puerta original, con gorroneras y pasadizo con mochetas. El pretil es obra reciente y no conserva, por tanto, ningún tipo de elemento defensivo. Si el terrado dispuso en la vertical de la puerta de ladronera o matacanes es un dato desconocido, ya que, como se ha señalado con anterioridad, es el lugar por el que el edificio quedó unido a la sacristía de la ermita.

La comunicación entre dicha azotea y la estancia abovedada de la torre se abrió en la cara SE de ésta, mediante un vano adintelado practicado en el muro. Su umbral se solventa de forma singular, recurriendo a un trozo de fuste granítico de acarreo.

\subsection{Análisis constructivo}

En todo el recrecido se aprecia una similitud tecnológica evidente en las soluciones constructivas empleadas, lo cual manifiesta una misma etapa edilicia. En esta nueva fase imperan materiales y fábricas que, dada su impersonal puesta en obra, nos impiden extraer de las mismas conclusiones cronológicas determinantes. De todas ellas se desprende la sensación de encontrarnos ante una obra poco cuidada y rápidamente ejecutada, aunque no por ello ha dejado de presentar un aceptable resultado estructural.

Los muros se ejecutan siguiendo el mismo grosor de los de la fase original. Se trata de una mampostería careada, no dispuesta en hiladas, y enripiada. Tan sólo de manera puntual se identifica algún sillar de acarreo de la fase islámica en los primeros metros de desarrollo del recrecido. Sí se aprecia un mayor esmero en las esquinas, para las cuales se destinan sillarejos labrados ex profeso, dispuestos formando un encadenado. Resulta cuanto menos curioso comprobar cómo en esta nueva etapa constructiva volvemos a encontrar elementos de acarreo preislámico formando parte de las fábricas. Tal es el caso, por ejemplo, de una pequeña estela que presenta una flor hexapétala, y que se sitúa en la esquina sur de la torre, próxima a su coronación. Como en el resto de la 
torre, los aparejos aparecen descarnados al exterior al haber desaparecido gran parte del revestimiento que, seguro, los cubriría en su origen, y del cual quedan escasos testimonios. Todas estas fábricas se toman mediante un mismo mortero calizo de grano sensiblemente más grueso que el que identificábamos en la obra islámica.

Con respecto a los abovedamientos que encontramos en esta segunda fase constructiva, su trazado y características particulares no vienen a aportar apenas luz sobre la cronología de la nueva obra, dado su concepto bastante común. La bóveda que cubre la estancia de la torre responde al modelo habitual de bóveda yarda, aunque en este caso se encuentra ligeramente rebajada. Poco más podemos aportar al respecto, dado que su aparejo se encuentra oculto actualmente bajo varias capas de enfoscado que cubren, además, toda la estancia. Cabe tan sólo señalar su similitud conceptual con la de la habitación del cuerpo mudéjar. Por otra parte, las nuevas bóvedas que cubren las idas de la escaleras, y, que como ya se refirió en su momento, son de medio cañón y directriz horizontal, se aparejan mediante mampuestos y lajas de piedra tomados con mortero de cal. Los extremos de estas bóvedas configuran sus roscas con un dovelaje pétreo de más fina labra, que contrasta con lo poco cuidado del resto de la construcción.

\section{SECUENCIA DE EVOLUCIÓN DIA- CRÓNICA}

Con independencia de las tradiciones que vienen a suponer un culto preislámico en este lugar de la ermita de Santiago del Camino de Medina Sidonia, aún no demostrado, el testimonio arquitectónico conservado in situ de más antigua filiación es el primer tramo de alzado de la torre. Una vez identificada esta construcción como un alminar de mezquita a partir de sus características tipológicas, morfológicas y edilicias, es menester que procedamos a su encuadre cronológico en virtud de dichos aspectos. Hemos de advertir, no obstante, que la labor de datación parte con un trabajo ya adelantado, pues en su momento ya recurrimos a la comparación con otros alminares más o menos fechados, de modo que únicamente será preciso que desgranemos lo ya expuesto con anterioridad. Pero, al contrario que se planteó en el anterior orden del discurso, ahora comenzaremos por los aspectos edilicios para luego confrontarlos con los datos referentes al tipo y a la morfología. Por otra parte, y en lo referente al encuadre cronológico de la torre como obra militar, no procederemos de igual modo que en la fase fundacional, dado lo impersonal de la nueva obra, por lo que tendremos que plantear hipótesis mediante el recurso casi exclusivo a las fuentes.

Referíamos cómo el aparejo de soga y tizón de este alminar de Medina Sidonia era un claro ejemplo, aunque algo tosco, de aquél que triunfó de forma sistemática en todo tipo de construcciones durante el Califato omega. La evolución experimentada por estas fábricas nos es de gran ayuda a la hora de concretar un momento de construcción para dichos paramentos. Comentábamos cómo la combinación de una soga con dos o tres tizones era común en obras oficiales a partir de las estructuras de Madinat al-Zahra' (comenzadas a edificar a partir de 325H/936), asociada, eso sí, a una mayor esbeltez de las testas y de la proporción general del sillar. El proceso de estilización de estas piezas pétreas será rápido, de modo que en el castillo de Tarifa ya encontramos el tipo de sillar que predominará hasta el comienzo de la fitna, mucho más menudo que el que triunfaba apenas treinta años atrás. En relación con los aparejos estudiados en otros alminares, referíamos cómo era inevitable la comparación con las torres de Santa Clara de Córdoba y San José de Granada, de finales del siglo X y primera mitad del siglo $\mathrm{Xl}$, respectivamente. Por otra parte, la organización general de la estructura de nuestro alminar, es decir, la forma de disponer los sillares en el muro perimetral y la resolución del abovedamiento según losas escalonadas que, a la vez, sirven para configurar el peldañeado, nos remiten nuevamente y de forma directa a ambas torres. De este modo, y desde un punto de vista edilicio, podríamos encuadrar nuestra construcción en torno al último cuarto del siglo $X$, tomando como tope la primera década del siglo XI, coincidiendo 
con el comienzo de la gran revuelta; durante la misma no creemos posible ningún impulso edilicio de envergadura. Tampoco se descarta que esta torre hubiera sido promovida en periodo taifa (ya citamos su relación con el alminar zirí de San José) aunque, desgraciadamente, poco sabemos acerca de la forma de construir en las taifas occidentales $y$, sobre todo, en la abbadí sevillana ${ }^{64}$; recordemos que este importante reino se anexionó el territorio de Sidonia a costa de los beréberes Banu Irniyyan en torno al año $458 \mathrm{H} / 10666^{65}$

En relación con la ubicación de la torre, tangente en el vértice septentrional del patio, recordaremos cómo este esquema es el habitual en las mezquitas andalusíes a partir de mediados del siglo $X$. Este valor post quem se relaciona a menudo con el hábito de alinear la torre con los muros perimetrales del patio, tal es nuestro caso. Respecto al tipo de alminar, éste de Medina Sidonia responde al modelo canónico de planta cuadrada que predominará hasta la desaparición de al-Andalus, aunque será, quizás, el machón nuclear el único elemento que nos pueda aportar algún dato destacado. En efecto, el replanteo cuadrado del mismo nos remite a una costumbre que se vuelve norma a partir de la segunda mitad del siglo $X$, coincidiendo con la construcción del alminar de Santa Clara de Córdoba; aunque existen otros ejemplos anteriores así resueltos, su carácter anecdótico, sobre todo en relación con la alta proporción de torres de machón cilíndrico documentadas, nos obliga a otorgar un término post quem a este elemento coincidiendo con la fecha propuesta. Otros detalles, como la presencia del vano de acceso axial orientado a mediodía, y el trazado de los tragaluces a modo de saeteras coincidiendo con la elimina- ción de un tizón, aparecen de forma idéntica en los ejemplares de Santa Clara y San José; a pesar de que ambas soluciones no condicionan cronologías, es menester referir nuevamente su comparación con aquellas construcciones.

De todo lo dicho se infiere que el margen cronológico propuesto en el estudio edilicio se confirma plenamente por los aspectos tipológicos y morfológicos, de ahí que, en efecto, pensemos que este alminar se construyó en un momento comprendido entre el último cuarto del siglo $X$ y el inicio de la fitna. Su similitud con los alminares de Santa Clara de Córdoba y San José de Granada nos obliga a considerarlos como sus paralelos más próximos, aunque el desconocimiento de la forma de construir en la zona durante periodo taifa, nos obliga a seguir insistiendo en la filiación propuesta. De este modo, el alminar de Medina Sidonia resultaría coetáneo de la torre cordobesa ${ }^{66}$, la cual, casi presentada como un modelo primigenio, no sería más que el trasunto de alguna otra erigida en torno a mediados del siglo $X$ (tal vez el alminar de la aljama de Madinat alZahra', a pesar de su machón ochavado).

Cabe referir, por último, la cuestión relativa a la orientación de la torre, ya que, no lo olvidemos, este tipo de construcción trazaba generalmente sus muros paralelos a los del resto del recinto de la mezquita. De este modo, y en virtud de la orientación de la qibla del oratorio, estableceremos un último control de tipo cronológico según el hábito predominante en el momento de construcción del alminar. No obstante, y como han demostrado las últimas investigaciones sobre el tema, las conclusiones tanto geográficas como temporales desprendidas de las mismas no arrojarán una gran uni-

64 Los recientes trabajos arqueológicos realizados en el alcázar de Sevilla no descartan la adscripción del segundo recinto del mismo a periodo taifa. Hemos de tener en cuenta que las fábricas identificadas en el mismo son parecidas en cuanto a su forma con las originales omeyas y apenas difieren métricamente. Véase el interesante estudio de M. Á. TABALES RODRÍGUEZ, "Investigaciones arqueológicas en el Alcázar de Sevilla", Apuntes del Alcázar de Sevilla, N I, Sevilla, 2000, pp. 24 a 26.

65 Véase, IBN IDARI, La caída del Califato de Córdoba y los Reyes de Taifa (al-Boyan al-Mugrib), est. y trad. de F. Malo Salgado, Salamanca, 1993, pp. 226 y 227.

66 Se propone la construcción de esta torre entre fines del siglo X o principios del siglo XI en V. ESCRIBANO UCELAY, Op. Cit., I96465, p. 85. Félix Hernández corrobora dicho margen temporal al proponer una cronología comprendida entre la muerte de al-Hakam II (Safar 366H/octubre 976) y la primera década del siglo Xl; consúltese, F. HERNÁNDEZ GIMÉNEZ, Op. Cit., 1975, p. 208. 
formidad ${ }^{67}$. La fachada SE de la torre, perpendicular a la dirección de la plegaria islámica, posee una orientación aproximada de $141^{\circ}$ (cifra referida a grados centesimales, $127^{\circ}$ en sexagesimales). Siguiendo el proceder expuesto por Alfonso Jiménez en su estudio sobre la qibla andalusí ${ }^{8}$, buscaremos en primer lugar el rumbo teórico de oración que corresponde al oratorio dada su situación; éste será aproximadamente de $109^{\circ}$. Así, el error que se deriva para nuestro caso será de $32^{\circ}$, cifra relativamente correcta para lo que predomina en las mezquitas andalusíes como norma general69. Aceptando la cronología propuesta para este alminar, comprobamos cómo dicho error coincide con la referencia de este último autor, según la cual "a partir del siglo $X$ se fueron orientando las aljamas y mezquitas nuevas de ciudades nuevas, o renovadas, de manera más adecuada" 70; atrás quedaban la mayoría de oratorios pretéritos que tendían claramente a mediodía. Esta clara desviación hacia el este del alminar de Medina Sidonia encaja, aunque justa, dentro de la orientación referida por Mónica Rius como "Tendencia hacia el este" de las mezquitas andalusíes ${ }^{71}$. Curiosamente, esta autora cita como únicas mezquitas del siglo $X$ adscritas a este grupo las de Madinat al-Zahra' y Santa Clara de Córdoba ${ }^{72}$, con independencia de un amplio conjunto de ellas que, aunque coetáneas, siguen la orientación establecida por la aljama cordobesa. Este detalle no sólo no distorsiona la cronología ya expuesta, sino que viene a reafirmar el paralelismo existente con el oratorio de Santa Clara.

Poco más sabemos acerca de la vida de la mezquita desde su fundación hasta la llegada de la frontera castellana a estas tierras por obra de Alfonso $X$ en 1264, momento en el cual pensamos que el culto primitivo queda interrumpido. En cualquier caso, no se descarta que para esa fecha la torre estuviera ya arruinada (véase supra). A la hora de establecer la secuencia de uso a partir de entonces, los aspectos tipológicos y constructivos de la torre en su recrecido como obra defensiva, apenas nos aportan datos sobre la cronología, de ahí que tengamos que centrarnos en lo que proporcionan las fuentes a la hora de fijar hipótesis. En efecto, la gran revuelta mudéjar del verano del año 1264 terminó de trastocar la fórmula de ocupación del territorio desarroIlada desde que Fernando III la llevara al valle del Guadalquivir, tarea culminada con la toma de Sevilla en diciembre de 1248. Ésta consistió en la ocupación de los núcleos urbanos, con el correspondiente establecimiento de guarniciones militares, mientras que el espacio rural conservaba su población andalusí, a veces mediante acuerdos de capitulación que no llevaban aparejados la ocupación militar del territorio y sus castillos ${ }^{73}$.

Desde la óptica del rey Sabio, este sistema no resultaba conveniente más que de manera provisional ante la necesidad de cubrir adecuadamente el flanco sur de Sevilla, entonces en proceso de repoblación. La proximidad del Estrecho y de dos potencias hostiles, la Granada nazarí y el Marruecos meriní, desaconsejaban que territorios tan extensos y cercanos a las ricas tierras del Guadalquivir continuasen en manos mudéjares, cuyos habitantes siempre tendrían excesivamente próximos a sus potenciales aliados en una hipotéti-

67 Véase, sin ir más lejos, lo concluido en dos recientes trabajos, A. JIMÉNEZ MARTíN, “La qibla extraviada”, Cuadernos de Madinat al-Zahra, Vol. 3, Córdoba, I99I, pp. 194 a 197, así como, M. RIUS, La alquibla en al-Andalus y al-Magrib al-Aqsa, Barcelona, 2000, pp. 104 a 122

68 A. JIMÉNEZ MARTíN, Op. Cit., 1991, p. 193.

69 Ibídem, 199 I, p. 195.

70 lbidem, 1991, p. 197.

7I Dichos oratorios parecen calcular su qibla según métodos astronómicos, o, en su caso, según el orto del sol en invierno (en torno a $120^{\circ}$ en al-Andalus); consúltese, M. RIUS, Op. Cit., 2000, pp. 106 y 107.

72 Ibidem, 2000, p. 110.

73 M. A. LADERO QUESADA y M. GONZÁLEZ JIMÉNEZ, “La población en la frontera de Gibraltar y el repartimiento de Vejer (ss. XIII y XIV)", Historia. Instituciones. Documentos, Vol. 4, Sevilla, 1977, p. 200. 
ca sublevación. Ésta se hizo realidad en 1264 , en buena medida como respuesta al cambio de status de los pobladores musulmanes de estas tierras, siendo rápidamente sometida la revuelta por el rey Sabio ${ }^{74}$. Desde entonces, Medina Sidonia y su alfoz no sólo quedaron integrados en la punta de lanza castellana orientada al Estrecho, sino que, repentinamente, se vieron convertidos en terreno propicio para las razzias meriníes que, desde 1275, asolaron la región con demoledora reiteración hasta $1340{ }^{75}$. La ruta fundamental de las algaras norteafricanas cruzaba el Estrecho hasta desembarcar en Algeciras y, por el camino de Tarifa, llegaba a las tierras bajas de La Janda, asolando los campos de Vejen Alcalá de los Gazules, Medina Sidonia, Jerez y Sevilla.

A pesar de estar consideraba la fortaleza de Medina Sidonia como integrante de la segunda línea defensiva de la frontera castellana frente al territorio islámico durante el reinado de Alfonso XI, a mediados del siglo XIV ${ }^{76}$, la amenaza de las cabalgadas enemigas pervivió durante largo tiempo. Todavía a comienzos del siglo $\mathrm{XV}$, los habitantes de la ciudad recibieron el privilegio de Juan II que les eximía del pago de servicio y montazgo por el traslado de sus ganados en caso de ataque granadino ${ }^{77}$. En este contexto situamos la fortificación del arruinado alminar, inmediatamente anterior a la construcción de lo que hemos venido en denominar "cuerpo mudéjar" y la más que probable reedificación de todo el templo, ahora ya bajo culto cristiano. La puesta en explotación de los campos circundantes de Medina Sidonia por los escasos repobladores que las mercedes reales conseguían atraer a estas tierras de frontera, requería de lugares fuertes, inmediatos a las explotaciones agrícolas, a los que acoger se ante la presencia de la caballería musulmana. Los muros de la ciudad no quedan lejos, pero la distancia es lo suficientemente grande para que los campesinos huidos de los campos que se extienden al sur de la misma no pudiesen franquearla a tiempo. De ahí la existencia del pequeño enclave fortificado, capaz de unas pocas personas, ya a la vista de las murallas de la ciudad. Este tipo de torres fuertes apenas si tenían capacidad defensiva ante un enemigo dispuesto a atacarlas. Sin embargo, podían suponer la diferencia entre la vida y la muerte ante una tropa de camino hacia otro objetivo y en un contexto de muchas construcciones de este tipo, según se explicará a continuación. Para las fuerzas implicadas en una cabalgada con destino a otro lugar, la detención en expugnar todos y cada uno de los lugares fortificados de un territorio fronterizo tan amplio como el que nos ocupa era una práctica por completo inusual. La multiplicidad de estos objetivos secundarios habría hecho imposible el cumplimiento de los que la expedición tuviese como fundamentales, toda vez que el factor tiempo corría en estos casos en contra del atacante: cuanto menor fuese la velocidad con la que alcanzasen su destino, mayor sería el tiempo para que se transmitiese la noticia del ataque, dando lugar a que los ganados y campesinos cristianos encontrasen refugio tras las murallas de castillos, villas fortificadas y ciudades; también, a que se organizase la defensa de estos lugares, haciendo acopio de provisiones y gentes de armas para afrontar un posible ataque; finalmente, a que el monarca castellano, las órdenes militares o los grandes señores tuviesen ocasión de reunir sus mesnadas para contrarrestar el ataque. Si el objetivo era la misma Medina Sidonia, como ocurriera en 1285 con las tro-

74 Crónica del rey don Alfonso décimo, Crónicas de los Reyes de Castilla, Biblioteca de Autores Españoles (B.A.E.),Vol. 66, Ed. Atlas, Madrid, 1953, p. I O. M. GONZÁLEZ JIMÉNEZ, "La obra repobladora de Alfonso X en las tierras de Cádiz", Cádiz en el siglo XIII. Actos de las Jornadas Conmemorativas del VII centenario de la muerte de Alfonso X el Sabio, Cádiz, 1983, pp. 9 a 12.

75 Crónica del rey don Alfonso décimo, Crónicas de los Reyes de Castilla, I, B.A.E.,Vol. 66, Ed. C. Rosell, Madrid, 1953, pp. 270 y 30 I; Crónica del rey don Sancho el Bravo, Crónicas de los Reyes de Castilla, I, B.A.E., Vol. 66, Ed. C. Rosell, Madrid, I953, p. 70; M. A. MANZANO RODRÍGUEZ, La intervención de los benimerines en la península Ibérica, Madrid, I992, pp. 82, 93, 244 y 25 I.

76 Véase, M. GARCÍA FERNÁNDEZ, El reino de Sevilla en tiempos de Alfonso XI (I312-1350), Sevilla, 1989, pp. 39 a 76.

77 Archivo Municipal de Medina Sidonia, Ejecutoria 1565, Ayllón, I4 de septiembre de 14II, trascrito y publicado en M. A. LADERO QUESADA y M. GONZÁLEZ JIMÉNEZ, Op. Cit., 1977, pp. 257 y 258. 
pas de Abu Ya'qub, el hijo del sultán Abu Yusuf, de nada habrían de servir este tipo de pequeños lugares fortificados.

Su singularidad no debe llamar a engaño. No debió ser la única torre fuerte de las inmediaciones, si bien su posterior uso como torre de la ermita ha garantizado su conservación. El recurso a la erección de torreones aislados o, más frecuentemente, adosados a casas, fue común en estas tierras de frontera. Su uso estaba muy extendido entre la población islámica, como señala la crónica de Hernando del Pulgar para tierras nazaríes. Conquistada Ronda por las tropas castellanas en 1485, "los moros, que sabían la tierra, se pusieron en las villas cercadas y en las muchas torres que hay en aquella serranía de Ronda, do se pudieron salvar" ${ }^{78}$. El mismo cronista describe las huertas de la hoya de Baza, "había más de mil torres pequeñas, porque cada vecino de aquella cibdad que tenía en ella alguna parte, facía una torre cercana a sus árboles (...).Y en cada pertenencia particular había tantos e tales edificios, que fortificaban toda la huerta" 79 .

Dada esta costumbre andalusí, el paisaje del entorno de Medina Sidonia debió contar también con otros edificios de esta tipología, obtenidos por los repobladores cristianos tras la referida revuelta mudéjar a la vez que el resto de las posesiones de sus primitivos habitantes. No debe extrañar tampoco su escasez en la actualidad, dada la tendencia regia a que fuesen arrasadas estas edificaciones tras la pacifi- cación del territorio. El fenómeno está bien documentado para tierras malagueñas en tiempos de los Reyes Católicos ${ }^{80}$. Sí han pervivido algunos topónimos en las inmediaciones de esta ciudad que apuntan en este sentido. Es el caso del cerro, cortijo y casa de la Atalaya, a $5 \mathrm{Km}$ al SO de la ciudad; el cerro de la Torre, a $13 \mathrm{Km}$, también al SO; cierta casa de la Alcaria, a 30 $\mathrm{Km}$ al SE; un cortijo de la Alcaria, a $8 \mathrm{Km}$ al S, así como el cortijo Torreón, a 18 Km hacia el E. Las instrucciones reales, dictadas en las Cortes para general conocimiento y cumplimiento, aluden también a los "alcaydes de los castillos y casas fuertes" del Reino, indicio indirecto de su numerosa existencia ${ }^{81}$. Las crónicas islámicas mencionan con frecuencia distintas bury o torres defensivas en los campos por donde realizaron sus correrías los jinetes meriníes en sus diversas campañas ${ }^{82}$. Únicamente cabe mencionar la singularidad de nuestro caso, pues la urgente necesidad de fortificar el territorio llevó a reaprovechar una construcción de uso religioso islámico, seguramente arruinada, como obra militar cristiana.

En el espacio histórico en el que proponemos encuadrar la fortificación del enclave se produjo un acontecimiento histórico de especial relevancia para Medina Sidonia y su entorno. Se trata de la fundación de la Orden Militar de Santa María de España por Alfonso X en 1272 , que nunca habría de contar con el beneplácito de Roma, uno de los motivos, sin duda, de su breve existencia ${ }^{83}$. La eficacia de estas instituciones monástico-castrenses animaron al rey

78 Consúltese, Crónica de Hernando del Pulgar, en Crónicas de los Reyes de España, B.A.E., Vol. 70, Madrid, 1953, p. 419.

79 Ibidem, 1953, p. 484.

80 J. M. RUIZ POVEDANO, "Problemas en tomo a la reestructuración del aparato militar defensivo en el occidente granadino a fines del siglo XV", Baetica, Vol. 2, Málaga, 1979, pp. 225 a 249. Los motivos que conducían al desmantelamiento de estas estructuras se centran en la conveniencia de eliminar lugares fuertes que pudieran servir de refugio a algún enemigo que pudiera apoderarse de ellos y, muy especialmente, para evitar la señorialización del territorio. Otra razón estribaba en el mal estado de algunos de estos edificios, lo que podría constituir un lugar de peligro potencial para los vecinos.

8I Archivo Municipal de Medina Sidonia, Ejecutoria 1565, Cortes de Burgos, 26 de febrero de I367, trascrito y publicado en trascrito y publicado en M. A. LADERO QUESADA y M. GONZÁLEZ JIMENEZ, Op. Cit., 1977, p. 249.

82 Véase, IBN ABI ZAR', Rawd al-qirtas, trad. A. Huici Miranda, Valencia, 1964, pp. 648 a 650.

83 J. MENÉNDEZ PIDAL, "Noticias acerca de la Orden Militar de Santa María de España instituida por Alfonso X", Revista de Archivos, Bibliotecas y Museos, Madrid, 1907, pp. 2 a 26. Véase también, para esta orden militar, J.TORRES FONTES, "La Orden de Santa María de España", Miscelánea Medieval Murciana, Murcia, 1977, Vol. 3, pp. 73 a II8, y R. SÁNCHEZ SAUS, "Las órdenes militares en la provincia de Cádiz", Cádiz en el siglo XIII. Actas de las Jornadas Conmemorativas del VII centenario de la muerte de Alfonso X el Sabio, Cádiz, 1983, pp. 56 a 60. 
Sabio a crear otra, de nuevo cuño, independiente de las ya muy poderosas de Santiago y Calatrava. Además de dedicarla a la Virgen María, de acuerdo con su personal devoción pretendió enfocarla a la actividad naval en el nuevo frente que se abría para Castilla: las costas meridionales de la Península, el estrecho de Gibraltar y, en definitiva, el dominio del paso marítimo por el que cabía temer la llegada de contingentes militares norteafricanos. El emblema de la nueva orden era una estrella de ocho puntas, imagen metafórica de la Virgen según recogen las Cantigas, de donde procede el nombre de Torre Estrella, fortaleza próxima a Medina y una de las posesiones de sus freires junto al Puerto de Santa María, Alcalá de los Gazules y la propia Medina Sidonia ${ }^{84}$. Ésta última habría de llamarse Estrella, pero el desastre de Moclín de 1280, que supuso un tremendo revés para la Orden de Santiago, habría de dar al traste con los proyectos reales. De inmediato se produjo la fusión entre los santiaguistas y la Orden de Santa María de España, sellando su temprana desaparición al ser nombrado maestre de la de Santiago quien ya lo era de la nueva, don Pedro Núñez. No deja de ser curioso que el nombre del conjunto edilicio que estudiamos, la ermita de Santiago del Camino, aluda a la orden de Santiago, heredera en estas tierras de la de Santa María de España. A este apóstol se encomendó la ciudad medieval ${ }^{85}$.

\section{CONCLUSIONES}

El alminar objeto de estudio es el único testimonio conservado de la existencia de una mezquita en el solar de la ermita de Santiago del Camino de Medina Sidonia. A pesar de la presencia de abundante material de acarreo de origen preislámico, ésta es la primera señal de ocupación confirmada en este lugar; mientras no se emprenda algún tipo de trabajo arqueológico que identifique una etapa anterior
El primer y fundamental análisis de esta construcción desde un punto de vista morfológico no ofrece dudas respecto a su uso fundacional como alminar. De este modo, se identifica perfectamente con un tipo arquitectónico muy específico y regido por singulares cánones, tanto es así, que es posible entenderlo dentro de una clara secuencia de evolución diacrónica, a pesar del conservadurismo formal que lo caracteriza en al-Andalus. Por otra parte, el estudio tecnológico nos ha permitido obtener una serie de conclusiones de notable interés con el fin de concretar una cronología aproximada del alminar. Entre ellas, serán tanto las soluciones constructivas generales como, principalmente, el aparejo de los muros, los principales elementos directores. Así, la cuestión de las fábricas nos ofrece un margen temporal muy preciso para su puesta en obra, al identificarse con la más clara ortodoxia constructiva califal. La organización de los sillares y sus proporciones nos remiten a un momento del último cuarto del siglo $X$; este margen coincide con los escasos aspectos cronológicos que se derivan de la morfología, emplazamiento y orientación, siempre menos precisos. De este modo parece evidente que nos encontramos ante un alminar erigido en pleno apogeo del Califato de Córdoba, aunque no disponemos de más datos referentes al resto del templo islámico. No sabemos si todo el conjunto fue construido mediante un único impulso edilicio en ese momento, o si, por el contrario, la torre responde a una renovación parcial de una mezquita más antigua.

En cualquier caso, hay algunos aspectos derivados de estas conclusiones que posibilitan ahondar tanto en la difusión de la arquitectura oficial cordobesa como en la peculiaridad de la organización del territorio en el entorno de Medina Sidonia. Con respecto a la primera de estas dos cuestiones, cabe apuntar que nos encontramos ante el único alminar califal identificado fuera de Córdoba con el característico aparejo a soga y tizón; posteriormente se

84 Archivo Ducal de Medina Sidonia, leg. 767, Sevilla, 10 de diciembre de 1279, trascrito y publicado en M. A. LADERO QUESADA y M. GONZÁLEZ JIMÉNEZ, Op. Cit., 1977, p. 229.

85 Ibidem, 1977, p. I4, nota I, en referencia un documento de la Biblioteca Nacional, Ms. 9.405, fol. 194. 
construirá la torre de San José de Granada, a modo de secuela de las artes edilicias omeyas en plena taifa beréber de los Banu Zirí. Es importante señalar que, hasta ahora, sólo se había identificado este tipo de construcción en la metrópoli, siempre vinculada de cerca al entorno del poder y a su arquitectura oficial, pero en nuestro caso no se emplaza siquiera en un medio urbano de cierto relieve, sino en un entorno rural relativamente alejado de la capital. Esto demuestra la extraordinaria difusión de unas formas constructivas, en principio vinculadas a la sede del Estado, que se desarrollan en un escaso margen de tiempo y que terminan por difundirse de una manera insospechada $y$ directa desde los talleres califales hasta ciertos medios campesinos controlados por los gobernadores omeyas. Ahora bien, iresponde este alminar a una obra oficial y es, por tanto, una fundación asociada directamente a la autoridad? Es difícil de precisar, aunque desde luego no creemos que esta construcción responda al prototipo de edificio promovido de forma oficial, aun a pesar de su cuidada puesta en obra; además, no se conserva resto alguno, textual o epigráfico, que avale tal tesis. Más bien hemos de hablar de una fundación ajena a esos intereses, circunstancia que no hace sino manifestar el grado de asimilación de este medio rural por parte del triunfante Estado Islámico que representa el Califato; y en esto tiene mucho que ver la fulgurante exportación, aunque no siempre de forma isótropa, de esa arquitectura que hasta entonces había ido madurando en las construcciones oficiales de Córdoba. Este alminar de Medina Sidonia sirve para reflejar ese sustrato tecnológico que la consolidación del Califato parece difundir y que se asentaría más allá de la metrópoli de forma tal vez habitual (aunque nos falten más ejemplos de carácter rural), y al margen de ciertas y puntuales fundaciones oficiales tales como recintos militares (Tarifa, Gormaz, etc.) y obras religiosas en mudun (Almería). Curiosamente, serán las obras castrales las que más rápidamente prescindan de ese carácter representativo que otorga la sillería califal, al incorporar otras técnicas más utilitarias y eficaces a su fin como la tabiya (véase Baños de la Encina, por ejemplo). En fin, y a la hora de justificar cómo la difusión de dichas soluciones constructivas está vinculada de alguna manera con la implantación del Estado omeya en el territorio, téngase en cuenta que esta característica fábrica de soga y tizón desaparecerá fulminantemente en las construcciones andalusíes a la vez que la fitna colapsa el poder califal. Estas fábricas sobrevivirán de forma residual en ciertas construcciones taifas como vemos en la Sevilla abbadí, en algunas construcciones ziríes de Granada o hammudíes de Málaga, para luego extinguirse definitivamente.

Otra cuestión de indudable interés reside en el papel que el edificio jugaría dentro de su entorno, y de qué forma se relacionaría con los aspectos poblacionales de la región, los cuales, y con los datos disponibles, resultan todo un enigma. Debe tenerse en cuenta, además, que no existe constancia arqueológica o cronística de enclave poblacional alguno de época islámica en el lugar de estudio. En cualquier caso, la propia entidad arquitectónica del alminar nos obliga a considerar un templo de unas dimensiones importantes, próximas, tal vez, a las vistas en las mezquitas mayores de Niebla - Almonaster, cuyas torres arrojan unas cotas similares a las estudiadas en nuestro caso. De este modo, estaríamos, efectivamente, ante una aljama que prestaría servicio a la población rural de las extensiones agrícolas inmediatas, organizadas en torno a alquerías, que evitarían acudir a los templos de la elevación inmediata donde se establece la Una. Siempre quedaría la opción de que la torre sirviera a una fundación tipo rábita o zawiya, de rancia tradición en el marco de la bahía gaditana, aunque la monumentalidad de la construcción, y su falta de identificación en este tipo de edificios, nos desaconseja considerar tal hipótesis. Nos encontramos así ante un caso parecido al estudiado en la mezquita califal de carácter rural asociada a un conjunto de explotaciones agrícolas que se da en la localidad almeriense de Velefique ${ }^{86}$, aunque, en nuestro caso, insis-

86 Véase, S. ANGELÉ y P. CRESSIER, Op, Cit, 1992, p. 259, 
timos, no está constatada arqueológicamente la existencia de dicho hábitat. Esta situación debe relacionarse con el práctico desierto estratégico de poblaciones menores que se establece en los territorios próximos al estrecho de Gibraltar durante el siglo XIII y que altera considerablemente la configuración del poblamiento local. Esa nueva coyuntura coincidirá con la renovación de la torre islámica como obra militar, para terminar por integrarse en el nuevo templo que adoptará el culto de los conquistadores castellanos.

\section{AGRADECIMIENTOS}

En primer lugar, y por su inestimable amabilidad, al Obispado de Cádiz, así como al ermitaño de Santiago del Camino de Medina Sidonia, Carlos García de Paredes y Núñez de Prado. Como siempre que se acomete cualquier tipo de investigación aparece detrás del papel escrito un grupo de colegas incondicionales y entusiastas sin cuya ayuda poco saldría a la luz; éstos son: Juan Carlos Guzmán Fernández, Beatriz Romero Gómez, Óskar Álvarez y Barrachina, Nieves Nieto Ortega y Carolina Longhurst. Esperamos que todos ellos se sientan partícipes de las páginas aquí presentadas. 


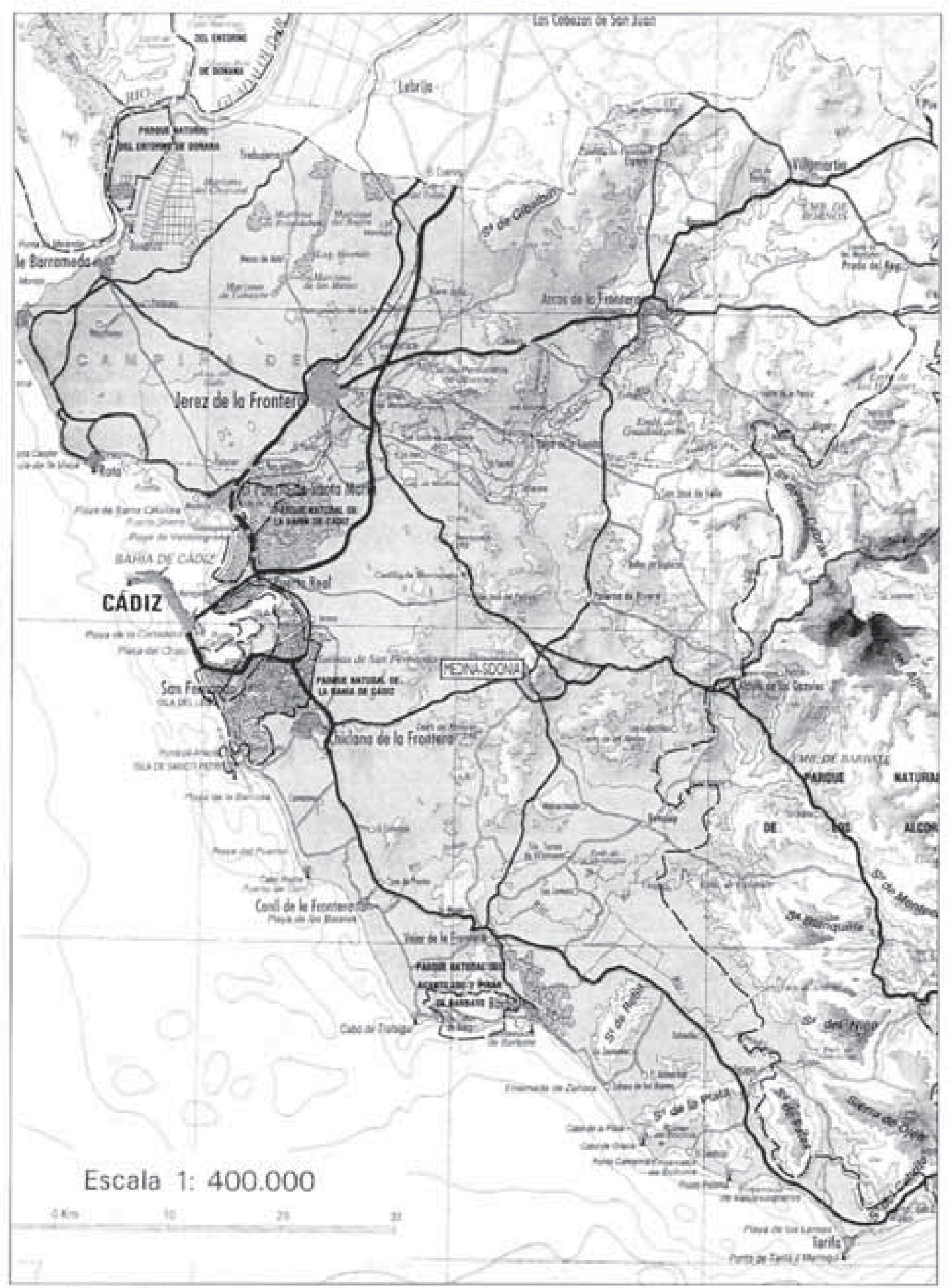

Figura I. Situoción de Medina Sidonia en la provincia de Codiz. En el plano original E I/400000 
Figura 2. Emplazamiento de la emita de Santiaga del Camino al SO de Medi. na Sidonia. En el piano on ginat E: $1 / 50.000$.
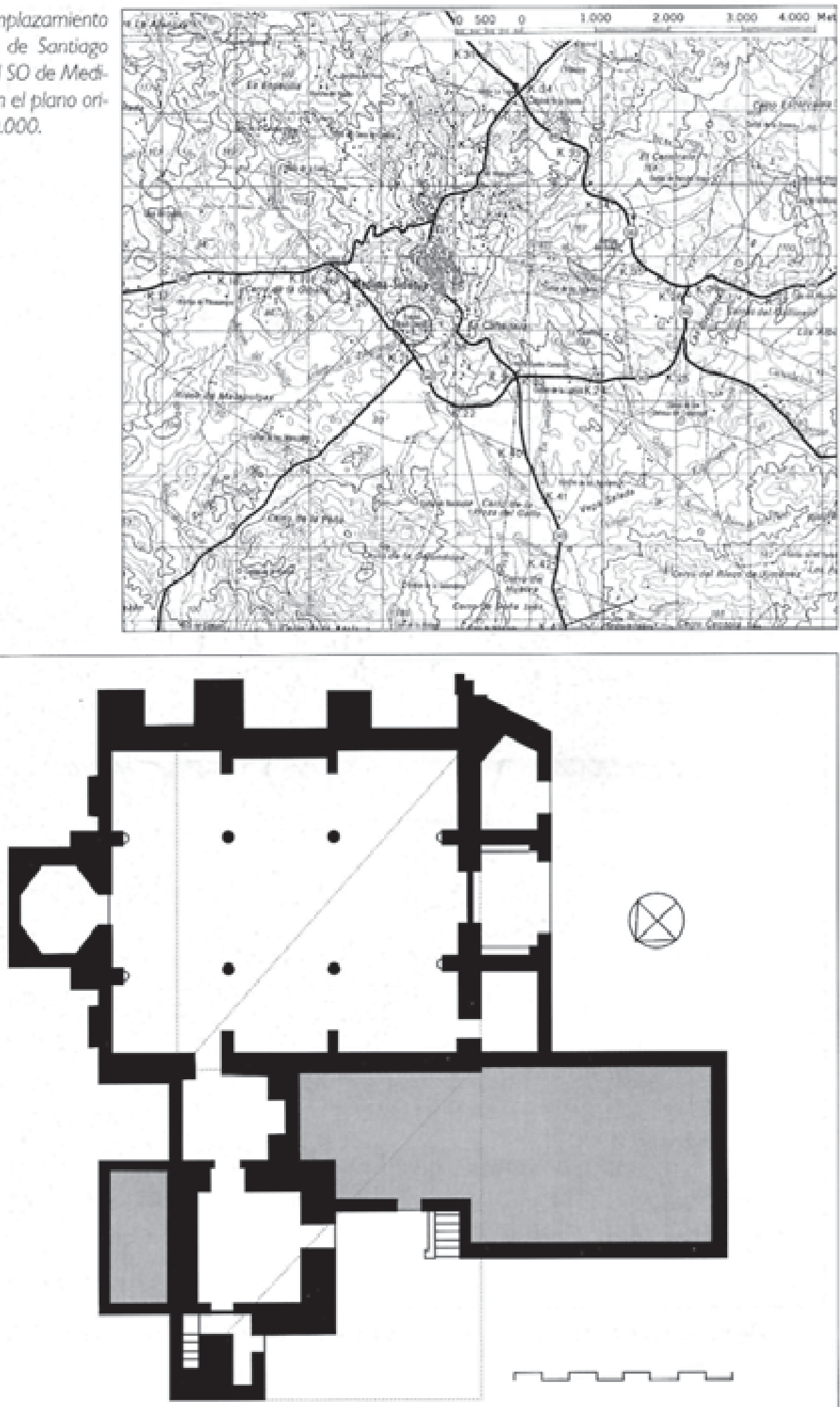

Figura 3. Croquis de la planta general de la emita de Santiogo del Camina. En trazo discontinua, hipotético trozodo de los muros del oratorio isí́mico. En gris, las construcciones añodidas durante el áltimo siglo. En el dibujo original E I/IS0. 


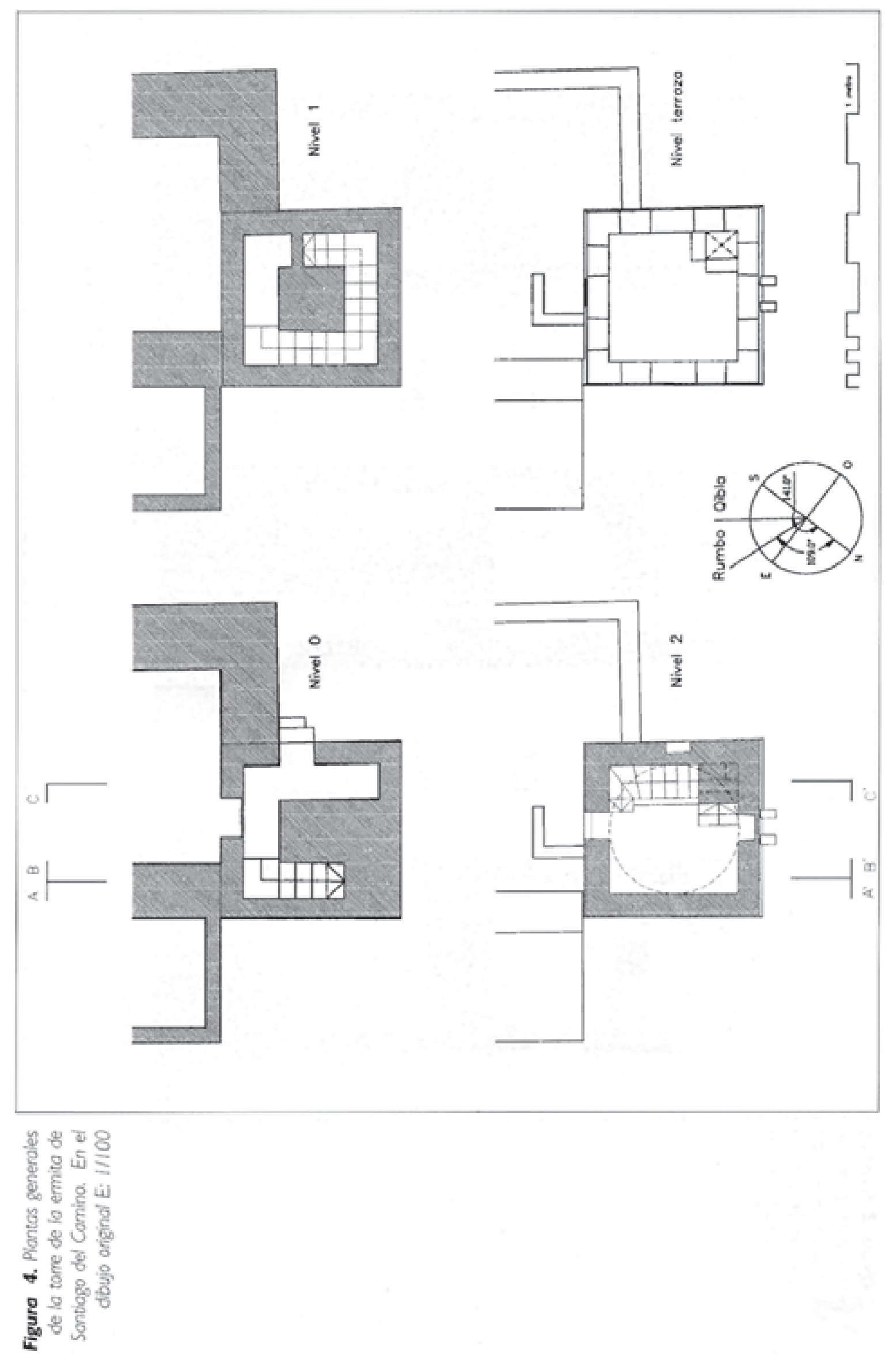




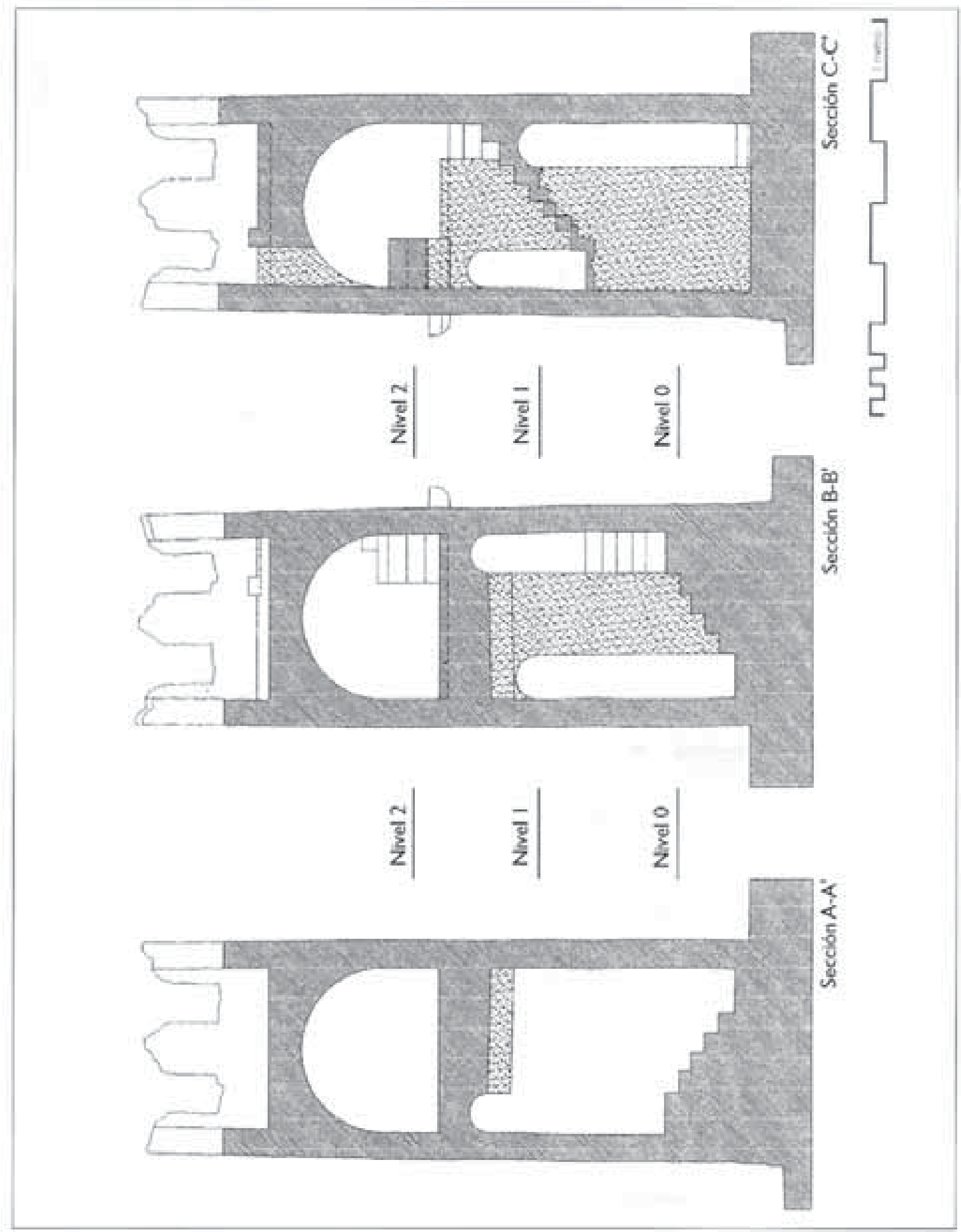

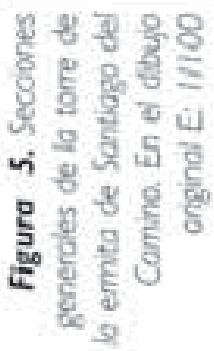




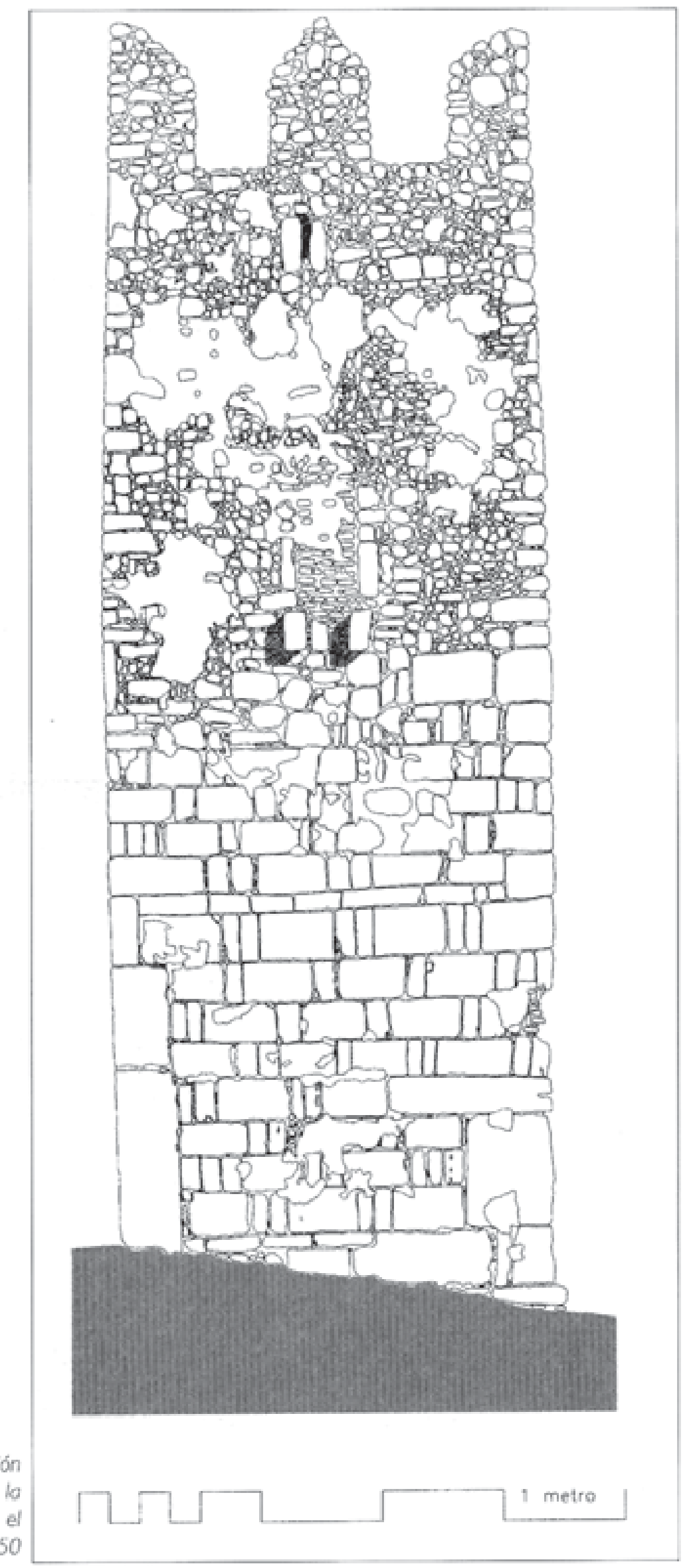

Figura 6. Restitución fotogramétrico de ko fochoda NO. En el dibujo oniginal E: 1/50 


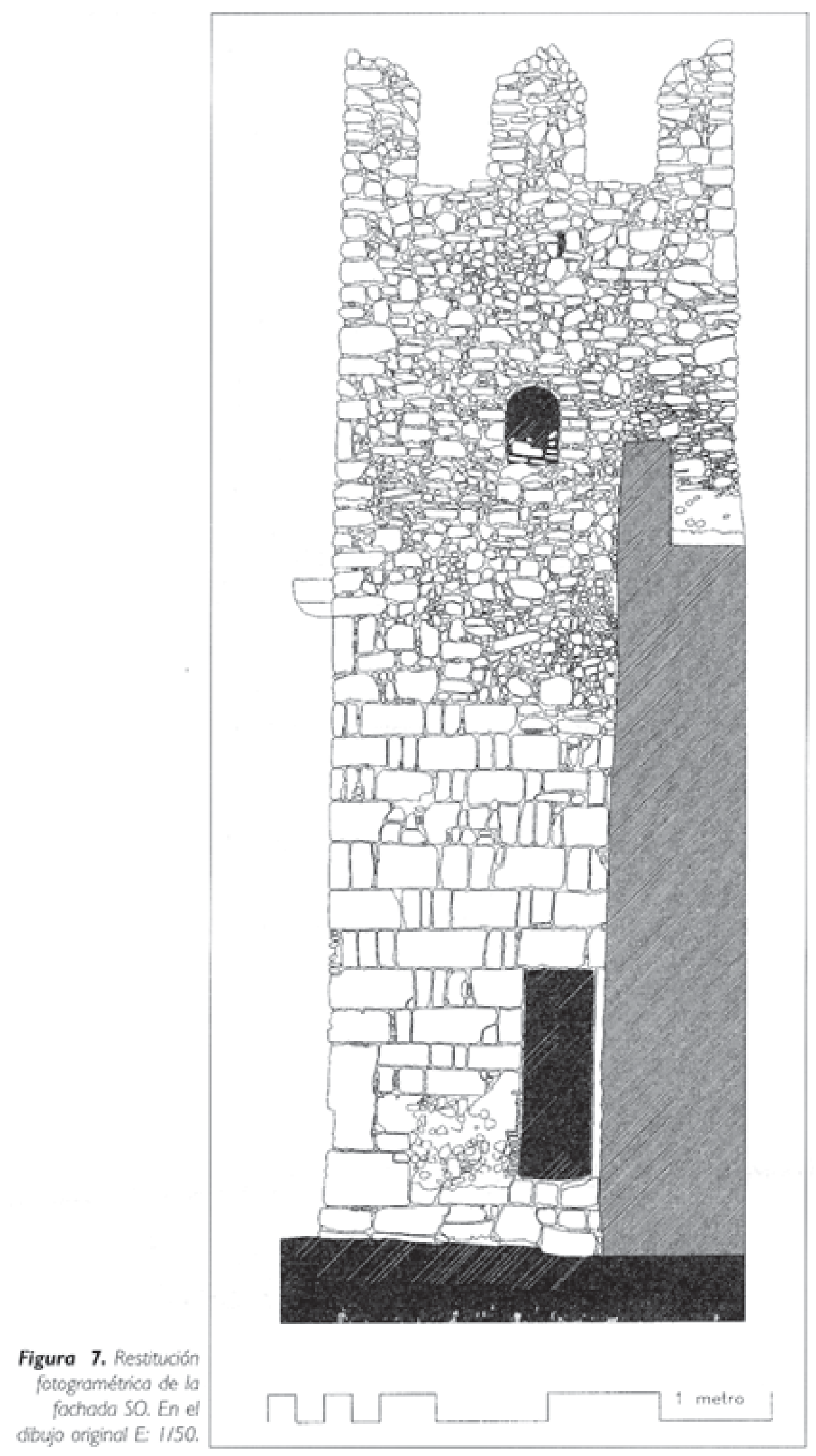




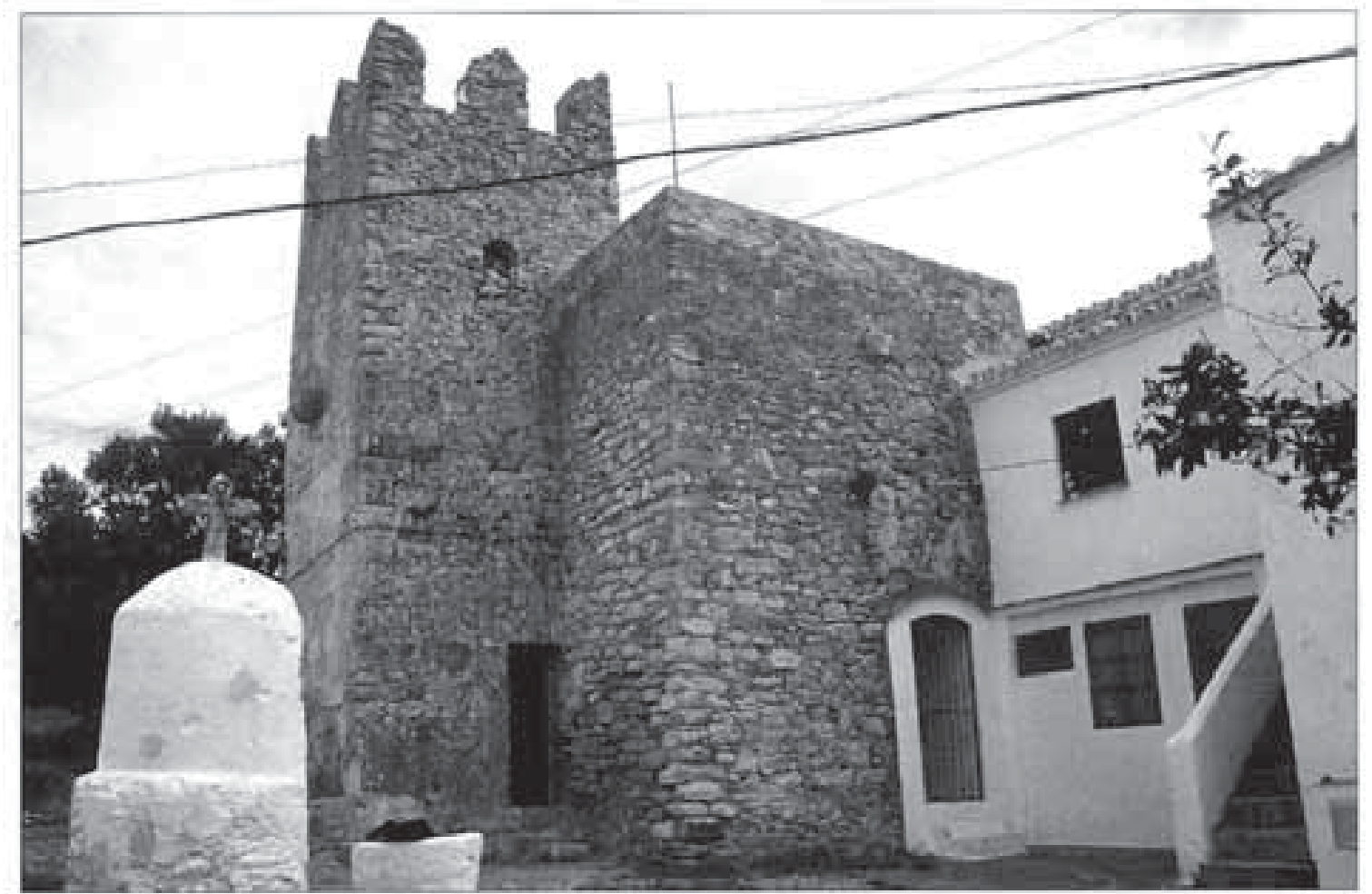

Lámina I. Vsta SO del cuerpo mudejar y la tome

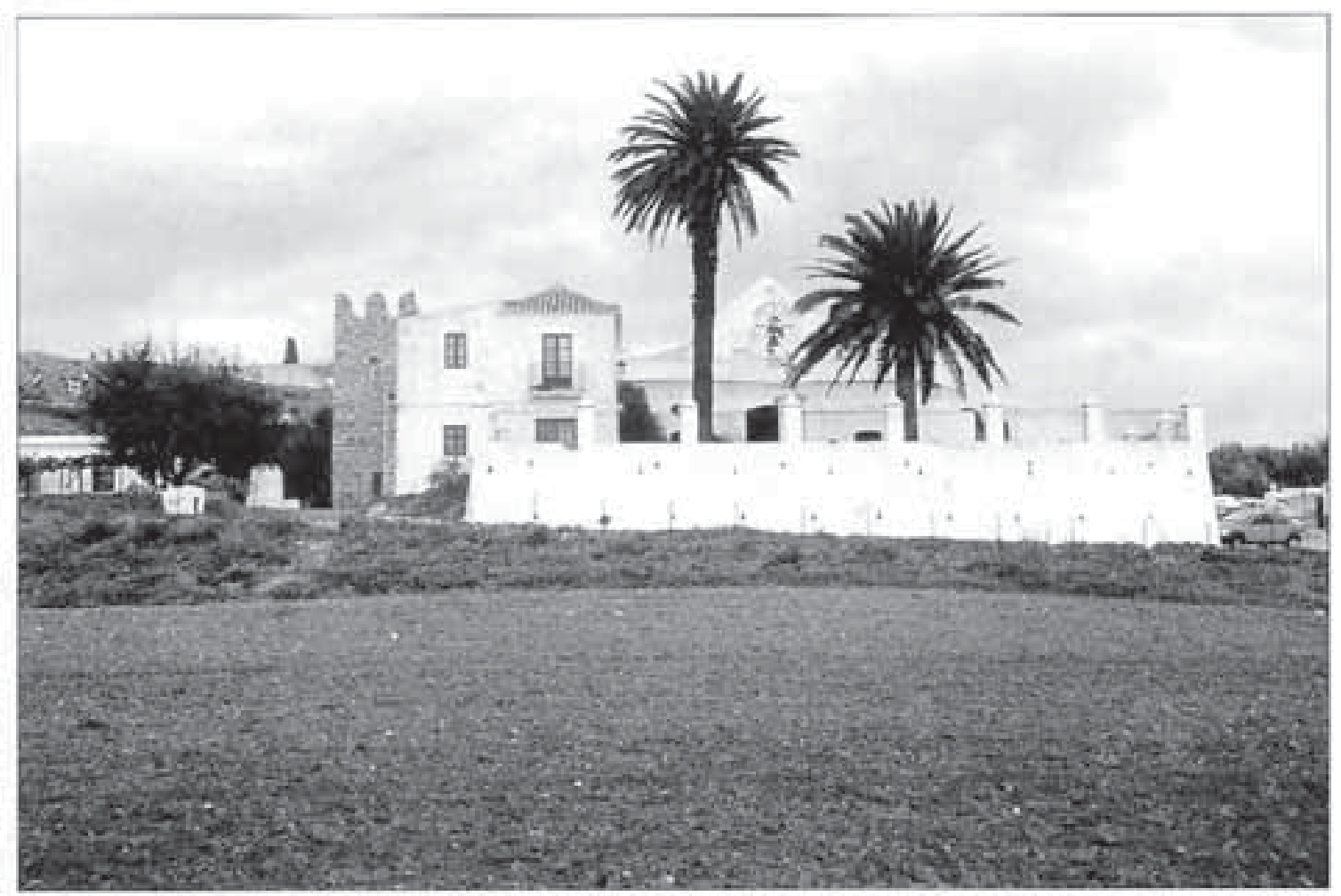

Lámina 2. Vista generat del conjunto de la emita de Santiago del Camino desde el SO, 
Lámina 3. Vista general de la torre de la ermito de Santiogo del Camino desde el $\mathrm{N}$.
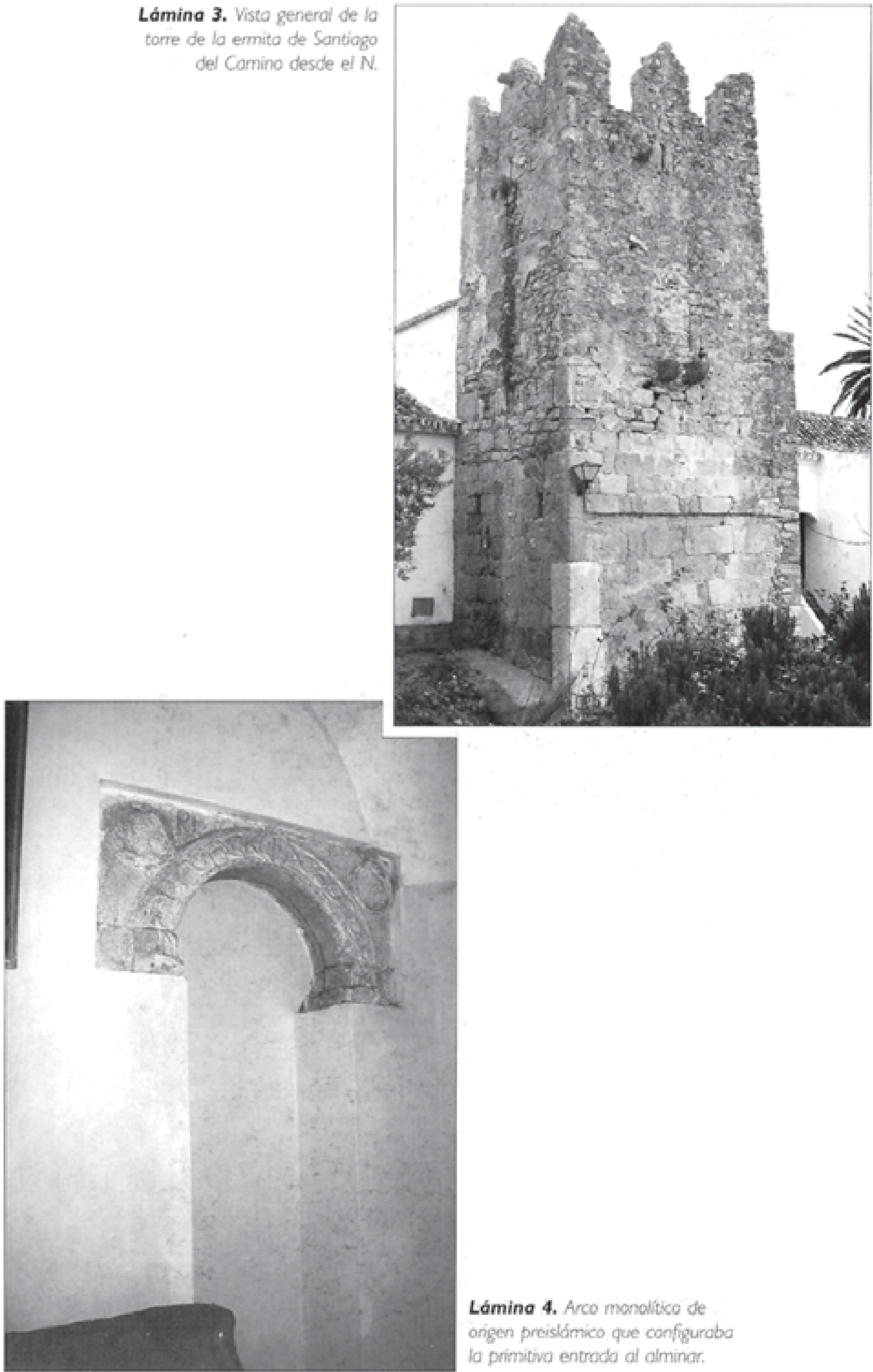

Lámina 4. Arco manolítico de arigen preislámico que configuraba la primitivo entrodo al alminar. 


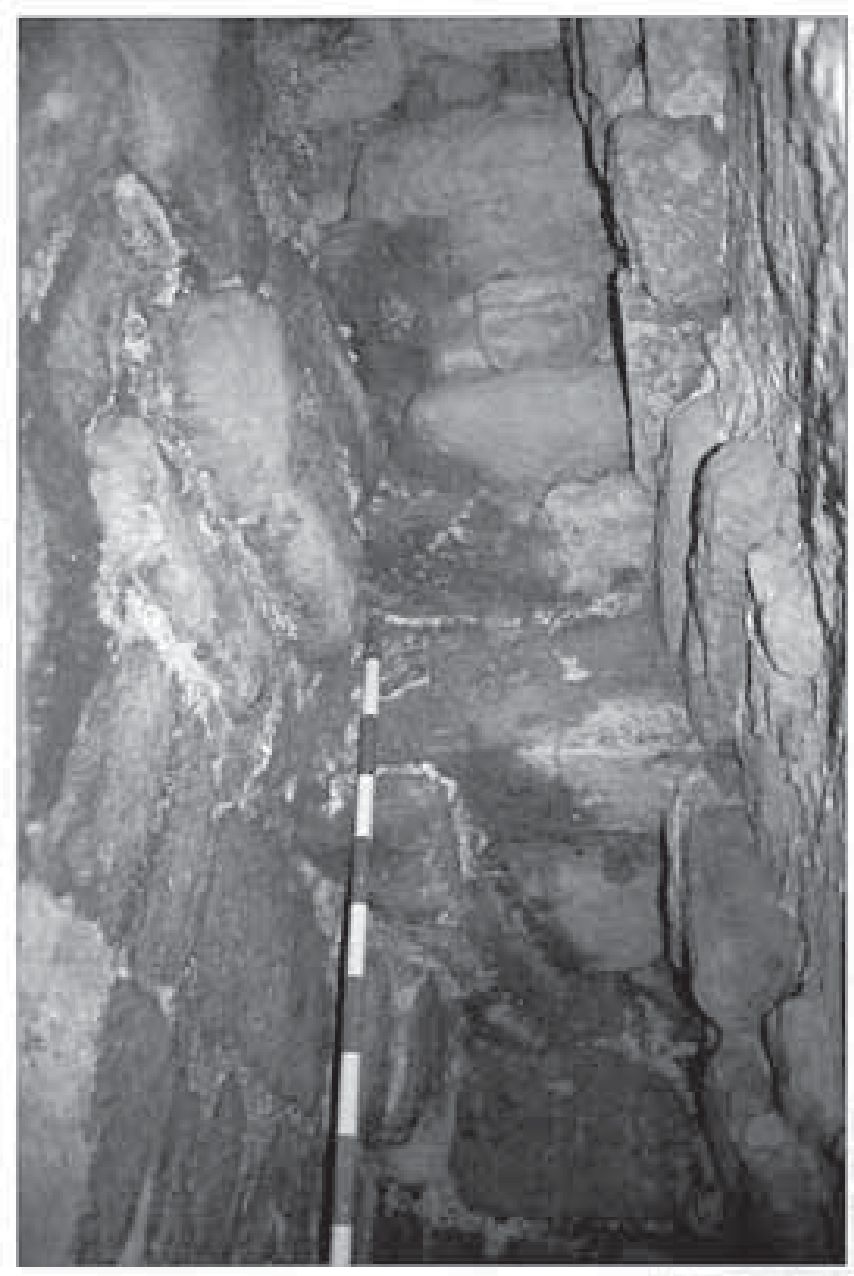

Lámina 5. Baveda escaionoda

istámica de losos de piedra

sobre minsulas.

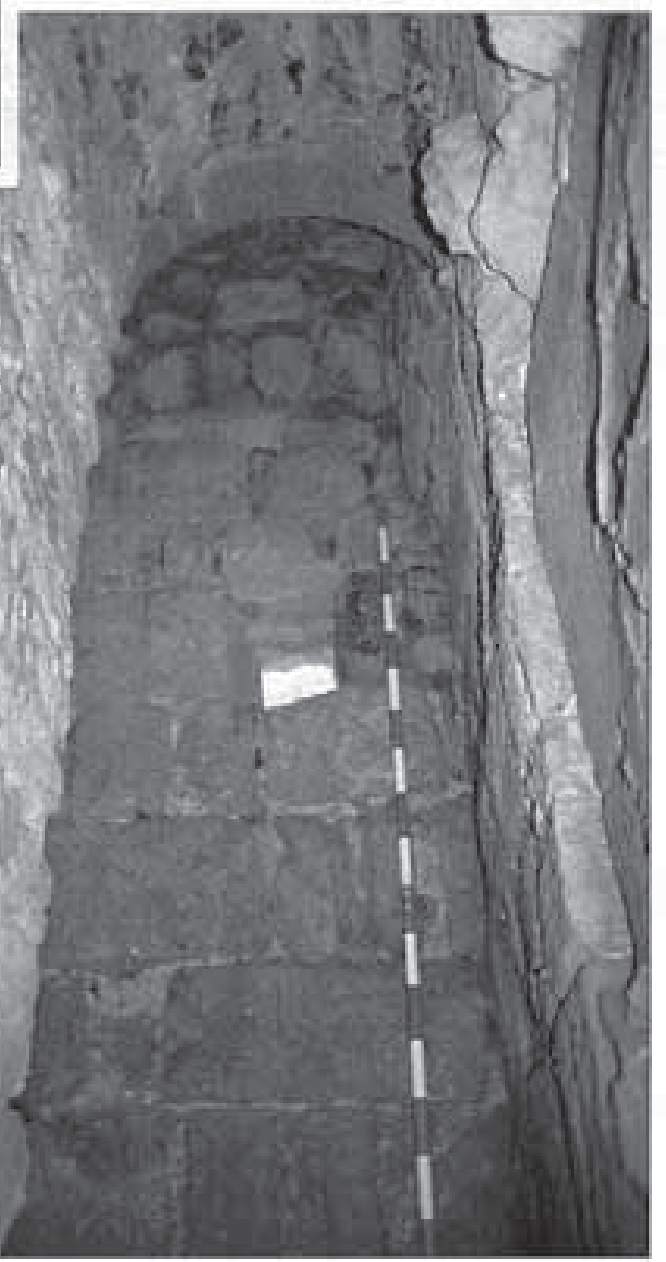

Lámina 6. Bobvedo de medio carhón en rearecido sobre la obra primitiva isłámico

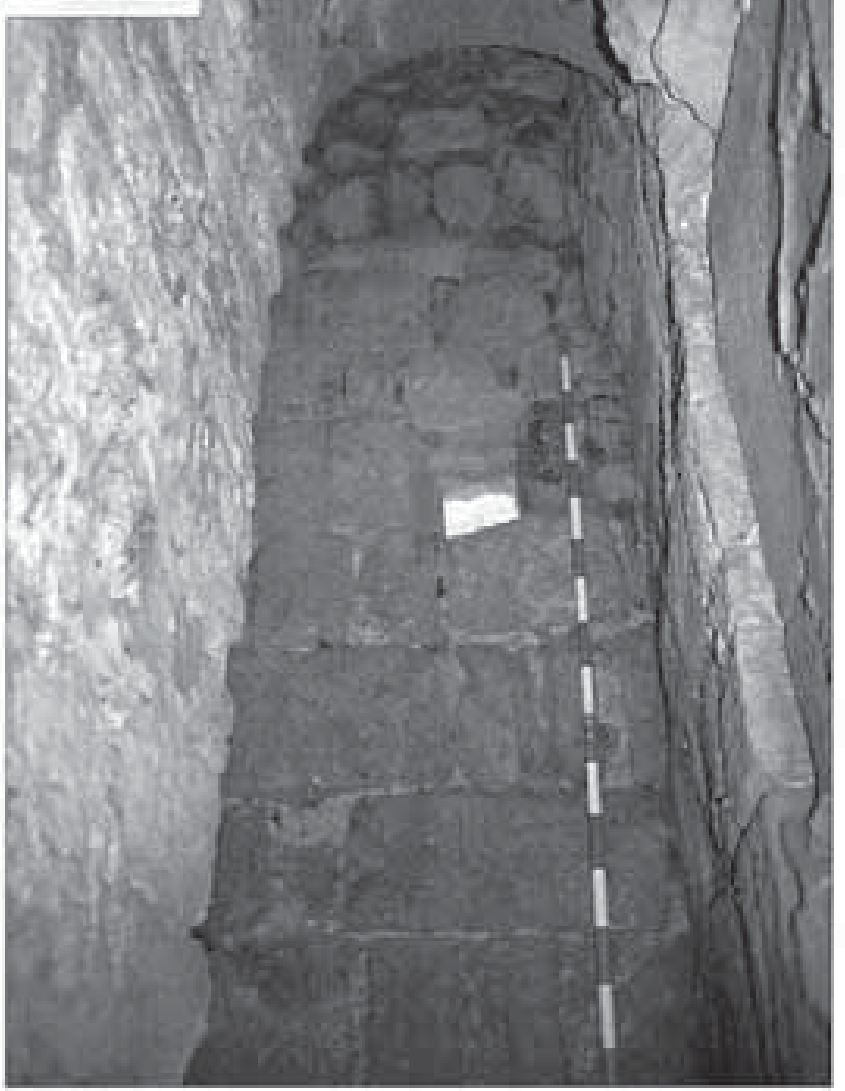




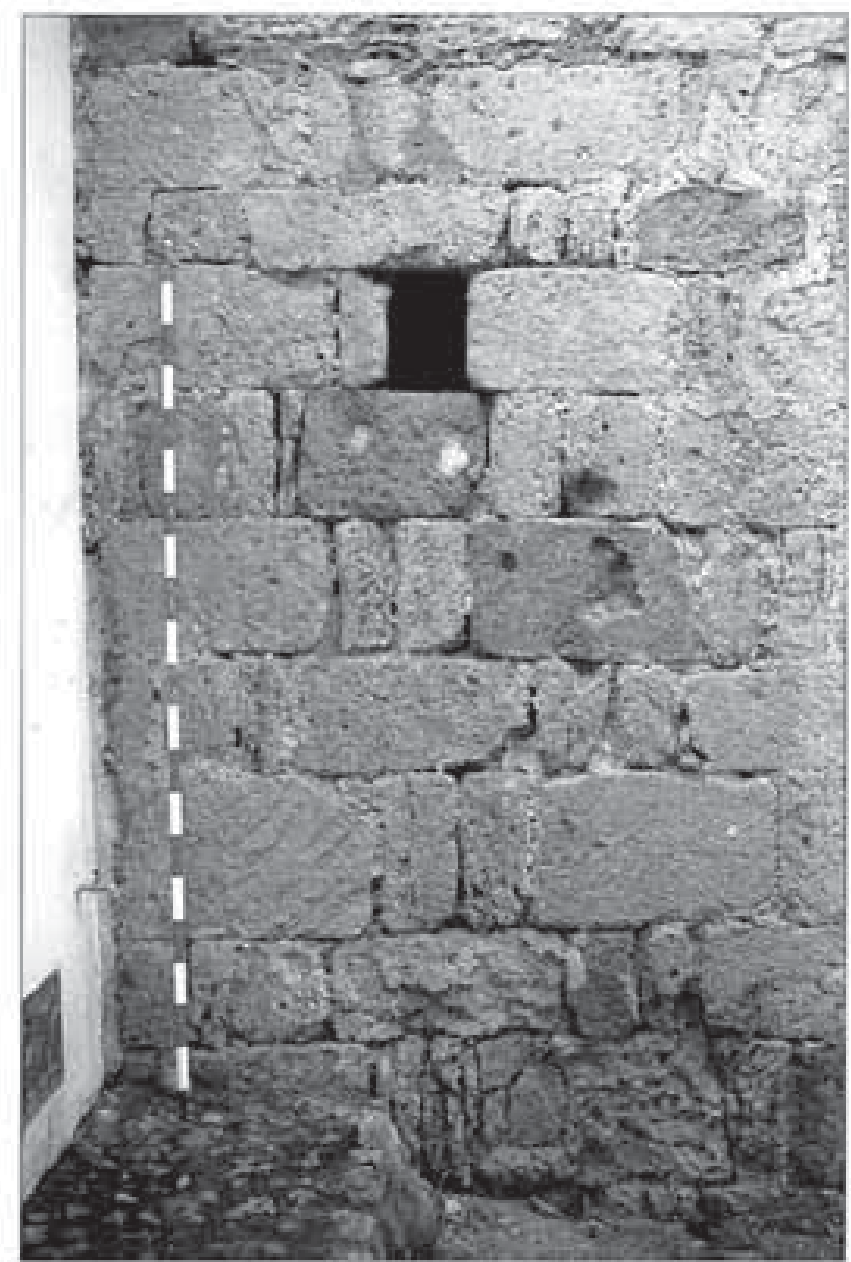

Lámina 7. Detalle de fobrica de silleria a soga y tizón en cara NE de la torre. Obsérvese el trapaluz formodo por la eliminación de un tizón.

Lámina 8. Detalle de la meriatura de fla

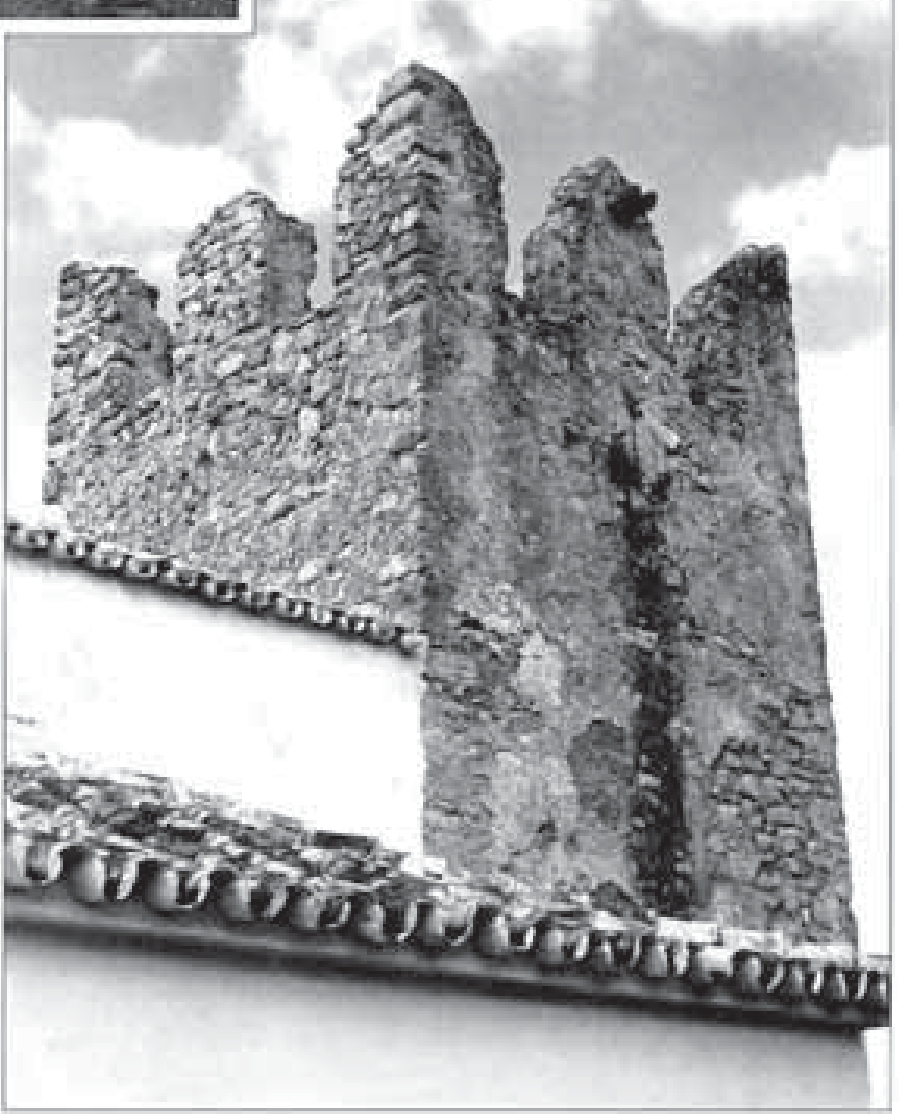

